\title{
Regulation of endogenous neural stem/progenitor cells for neural repair-factors that promote neurogenesis and gliogenesis in the normal and damaged brain
}

\author{
Kimberly J. Christie and Ann M. Turnley*
}

Neural Regeneration Laboratory, Department of Anatomy and Neuroscience, Centre for Neuroscience Research, The University of Melbourne, Parkville, VIC, Australia

\section{Edited by:}

Clare Parish, Florey Neuroscience

Institute, Australia

\section{Reviewed by:}

Mohamed Jaber, University of

Poitiers, France

Michael Chopp, Henry Ford Health

System/Henry Ford Hospital, USA

*Correspondence:

Ann M. Turnley, Department of

Anatomy and Neuroscience,

Melbourne Brain Centre,

Royal Parade at Genetics Lane,

The University of Melbourne

Parkville, VIC 3010, Australia.

e-mail: turnley@unimelb.edu.au
Neural stem/precursor cells in the adult brain reside in the subventricular zone (SVZ) of the lateral ventricles and the subgranular zone (SGZ) of the dentate gyrus in the hippocampus. These cells primarily generate neuroblasts that normally migrate to the olfactory bulb $(\mathrm{OB})$ and the dentate granule cell layer respectively. Following brain damage, such as traumatic brain injury, ischemic stroke or in degenerative disease models, neural precursor cells from the SVZ in particular, can migrate from their normal route along the rostral migratory stream (RMS) to the site of neural damage. This neural precursor cell response to neural damage is mediated by release of endogenous factors, including cytokines and chemokines produced by the inflammatory response at the injury site, and by the production of growth and neurotrophic factors. Endogenous hippocampal neurogenesis is frequently also directly or indirectly affected by neural damage. Administration of a variety of factors that regulate different aspects of neural stem/precursor biology often leads to improved functional motor and/or behavioral outcomes. Such factors can target neural stem/precursor proliferation, survival, migration and differentiation into appropriate neuronal or glial lineages. Newborn cells also need to subsequently survive and functionally integrate into extant neural circuitry, which may be the major bottleneck to the current therapeutic potential of neural stem/precursor cells. This review will cover the effects of a range of intrinsic and extrinsic factors that regulate neural stem/precursor cell functions. In particular it focuses on factors that may be harnessed to enhance the endogenous neural stem/precursor cell response to neural damage, highlighting those that have already shown evidence of preclinical effectiveness and discussing others that warrant further preclinical investigation.

Keywords: neural stem cell (NSC), neural precursor cell (NPC), neural stem/precursor cell (NSPC), neurogenesis, gliogenesis, traumatic brain injury, ischemic stroke, subventricular zone (SVZ)

\section{INTRODUCTION}

The concept that the adult mammalian brain contains populations of resident neural stem/progenitor cells (hereafter collectively referred to as NSPCs) was generally accepted two decades ago (Reynolds and Weiss, 1992; Richards et al., 1992), although first shown by Altman and Das in 1965 (Altman and Das, 1965). Adult neurogenesis occurs primarily in two neurogenic regions in the brain, the subventricular zone (SVZ) of the lateral ventricles and the subgranular zone (SGZ) of the dentate gyrus in the hippocampus. To produce new neurons a NSPC must go through a process of proliferation, migration, differentiation, and integration to become a productive member of existing circuitry in the brain. Under normal physiological conditions adult NSPCs predominantly produce neurons, in particular interneurons in the olfactory bulb $(\mathrm{OB})$ for SVZ-derived cells and dentate gyrus granule cell neurons for SGZ-derived cells. Following neural damage, however, SVZ-derived cells have the capacity to respond to the insult and produce neurons as well as astrocytes and oligodendrocytes. Harnessing this ability of NSPCs to produce new neuronal and glial cells as a means to replace cells damaged or lost following neural injury or disease to promote neural repair has been the focus of a substantial body of research. There are four main areas in the life cycle of a NSPC that can be targeted to try to enhance neural repair, namely proliferation, migration, differentiation (and specific cell type generation), and survival/integration. However, the field is full of conflicting reports on the benefit and ability of NSPCs to recover function following a range of injuries and diseases. While many labs have reported an increase in proliferation of neuroblasts and even migration to injured areas, a large part of the problem may lie in the failure of newly generated neurons to integrate into existing neural circuitry and survive past 4 weeks or so after their generation. Augmentation of all steps of the process of neurogenesis would ideally lead to an increased benefit following injury, but ultimately the cells must integrate and survive to have a functional benefit.

This review will cover some of the main factors known to be involved in neurogenesis and gliogenesis in the adult CNS and in particular those that have been shown to play a role in neural 
repair. It will also explore how inflammatory mediators and other injury-related factors may modify the NSPC response to neural damage. We will not undertake a comprehensive review of factors regulating neurogenesis and gliogenesis in the normal developing or adult brain, as there have been several recent and comprehensive reviews covering this area (e.g., Guillemot, 2007; Ming and Song, 2011; Faigle and Song, 2012). Rather, we will highlight factors that play a role in regulation of normal adult NSPC function and which have been shown to be modulated to enhance repair following neural damage. Table 1 summarizes the factors discussed, which NSPC populations are affected (SVZ or SGZ), the type of neural injury, if any and the NSPC function affected. Figure 1 depicts the effects of extrinsic factors on the SVZ-derived NPC response to injury.

\section{NSPC FATE: NORMAL NEUROGENIC NICHES vS. THE INJURED CNS ENVIRONMENT}

Although the bulk of neurogenesis and gliogenesis occurs during embryonic and early postnatal development, NSPCs continue to produce neural cells in the adult brain. Importantly for the purpose of harnessing adult NSPCs for neural repair, unlike during development, the vast majority of adult-derived cells are fated to a neuronal lineage, with a much smaller percent differentiating into oligodendrocytes in the normal adult brain. In general, the diversity of cell types and neuronal subtypes that can be spontaneously generated by adult NSPCs is substantially limited compared to embryonic cells. This is probably largely due to a less permissive adult environment rather than a constitutive feature of the NSPCs themselves, as under appropriate conditions, such as in neurospheres in vitro (Reynolds and Weiss, 1992) or following ablation of neuronal populations without inflammatory system activation (Magavi et al., 2000), the ability of adult NSPCs to produce different neural cell types has been demonstrated. The more restricted fate of adult NSPCs in the normal adult CNS reflects the relative paucity of growth and neurotrophic factors compared to during development. The presence of inhibitory/attractive substrates, such as in the RMS, to constrain migratory routes and the lack of available space in the adult circuitry to allow integration of newborn cells, in general restricts normal NSPC function to neurogenic regions and currently limits the ability of endogenous NSPCs to replace specific neuronal or glial types in different regions in the CNS.

To further complicate matters, the injured adult CNS is an entirely different environment to the normal adult neurogenic niche or the developing nervous system, with substantial influence on NSPC function that in some instances appear to override the normal program of NSPC fate. This is particularly the case for SVZ NSPCs, which, as detailed further below, can be induced away from their normal migratory route to the OB toward the site of neural damage, a process largely induced by inflammatory mediators. After successful migration to the correct location, new neuroblasts must differentiate into the proper phenotype of neuron and integrate into local circuitry. The local circuitry to be repaired will depend on the type of damage, be it ischemic, traumatically injured or neurodegenerative, with some common factors and others specific to the site and type of damage. Effects of exogenous factors have been variably examined in each of the above types of neural damage and are described below for the relevant factors.

The majority of research on ectopic migration and neural differentiation of SVZ-derived NSPCs following neural damage has been performed by use of ischemia models and has demonstrated that cells do indeed reach the injured parenchyma (Arvidsson et al., 2002; Parent et al., 2002; Jin et al., 2003; SundholmPeters et al., 2005; Ohab et al., 2006; Yamashita et al., 2006; Cayre et al., 2009; Young et al., 2011). It appears that the cells in general no longer migrate in a chain formation and carry on individually, with some reports describing an increase in progenitor numbers without an effect on numbers of cells in the RMS (Zhang et al., 2001b), while others report that the response to injury is at the expense of the RMS population (Jin et al., 2003; Goings et al., 2004). This change in migration is the direct result of chemoattractive cues expressed from the injury site. As detailed further below, chemokines and their receptors can attract neuroblasts from the RMS. For example, Stromal cell-derived factor-1/CXCL12 and its receptor CXCR4 are upregulated at the injury site (Imitola et al., 2004; Robin et al., 2006) and expression of several other chemokines and their receptors are upregulated on adult NSPCs by inflammatory cytokines, such as IFN $\gamma$ and TNF $\alpha$ (Turbic et al., 2011).

In general ischemia models have demonstrated production of new neurons from the SVZ in damaged cortex or striatum, while injury of the cortex usually promotes the generation of astrocytes and microglia/macrophages at the site of injury, with few or no new neurons produced (Ramaswamy et al., 2005; Richardson et al., 2007; Kreuzberg et al., 2010; Blizzard et al., 2011; Zhang et al., 2011). Neurodegenerative disease models, such as Parkinson's disease (PD) models, have also demonstrated migration of SVZ NPCs to the site of damage, with production of neurons in some cases but not others (Cooper and Isacson, 2004; Kadota et al., 2009; Jing et al., 2012). The production of astrocytes and oligodendrocytes near the injury site may be a result of expression of repressors of neuronal fate (Kernie et al., 2001; Shear et al., 2004; Buffo et al., 2005). Further, as detailed below, administration of a variety of factors promotes neurogenesis and/or gliogenesis in these normally non-neurogenic sites. The SVZ-derived NSPC response and the new cells they produce is quite variable, depending on injury type, region of neural damage, species and likely a range of other factors that remain to be defined.

There is little/no evidence that SGZ hippocampal NSPCs can migrate away from their normal GCL fate; however they do respond to neural damage (Dash et al., 2001; Chirumamilla et al., 2002), even if the hippocampus is not directly affected by damage, such as in cortical impact models (Kernie et al., 2001). This leads to alterations in neurogenesis that can produce altered cognition and/or effects on memory and anxiety. Little is currently known about how this neurogenesis is altered, but will be touched on below.

\section{TRANSCRIPTION FACTOR REGULATION OF NSPC FUNCTION}

Factors intrinsic to the cell participate in multiple roles of neurogenesis from proliferation to differentiation. Generally, transcription factors are the most widely studied intrinsic factors 
Table 1 | Extrinsic factors affecting SVZ and SGZ NSPC responses under basal conditions and following neural damage.

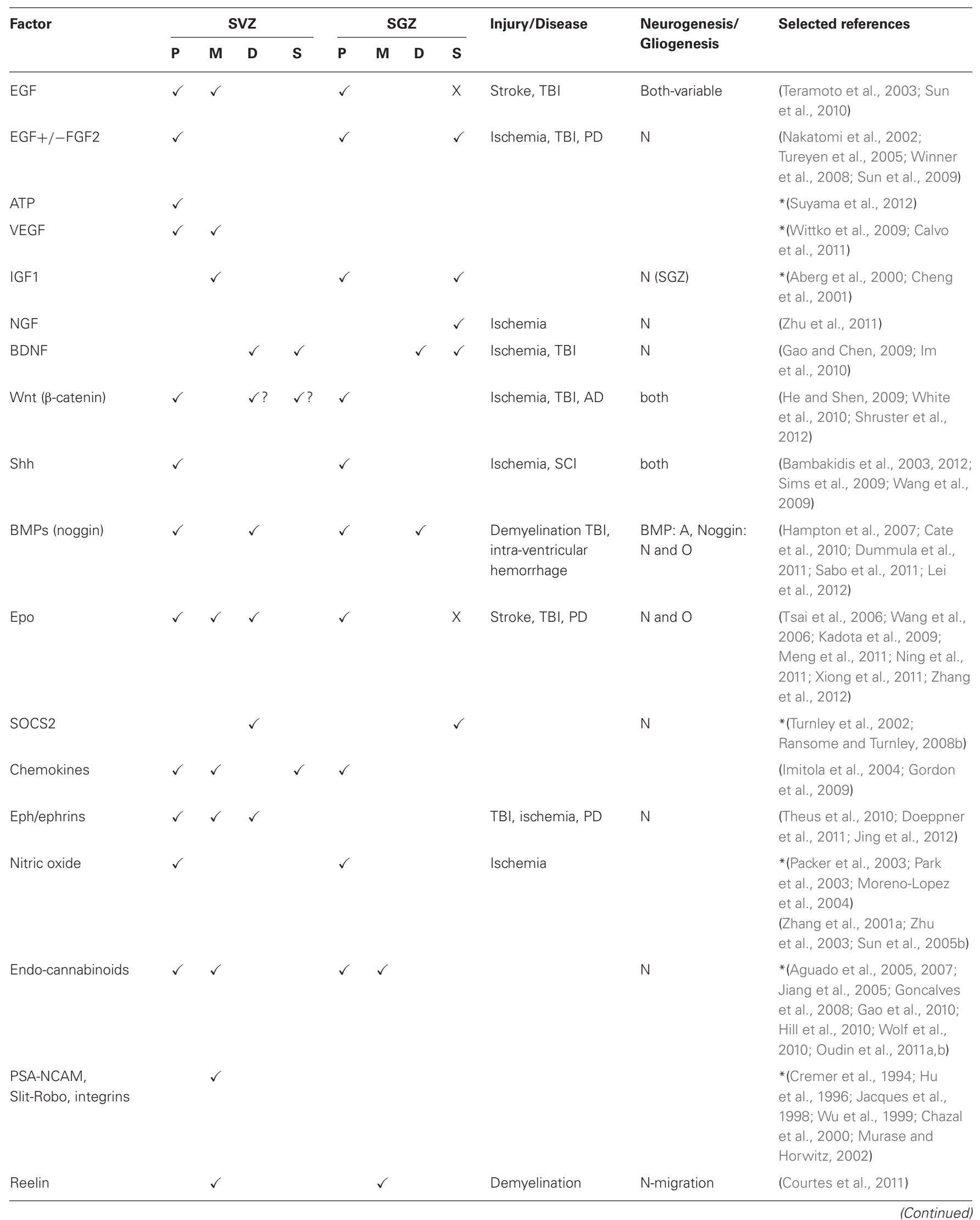


Table 1 | Continued

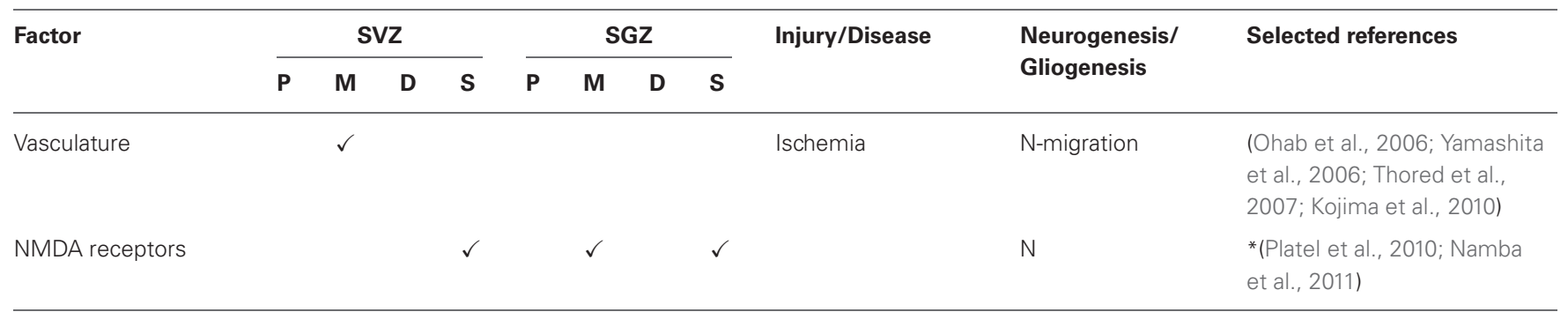

P, Proliferation; M, Migration; D, Differentiation; S, Survival; N, Neurogenesis; O, Oligodendrogliogenesis; A, Astrogliogenesis; TBI, traumatic brain injury; $P D$, Parkinson's disease; $A D$, Alzheimer's disease; SCl, spinal cord injury; * references for basal non-injury conditions.

researched in adult NSPCs and many are similar to programs for neurogenesis during development. However, while a substantial amount of information is known about the role that different transcription factors play in modulation of NSPC biology, much less is known about extrinsic factors that can be used to alter expression of the transcription factors to produce desired specific functional outcomes. This section will discuss the expression and roles of some transcription factors that may be useful therapeutic targets. Later sections will discuss effects of different extrinsic growth factors and cytokines, with particular reference to their role following neural damage, although there are currently few links described between these factors and expression of specific transcription factors in the adult NSPC or newborn neural cells.

\section{SVZ}

Under basal conditions, NSPCs produced in the SVZ go on to form neuroblasts that migrate from the lateral ventricles along the rostral migratory stream (RMS) to the OB where they differentiate into neurons of the OB. The formation and proliferation of NSPCs is dependent on the Sox family of genes, in particular Sox2. The zinc-finger protein Ars2 (arsenite-resistant protein 2) controls the multipotent progenitor state of NSCs through activation of Sox2 (Andreu-Agullo et al., 2012). c-Myb is required for maintenance of the neural stem cell niche, promoting expression of Sox 2 and Pax6 and subsequent proliferation (Malaterre et al., 2008). Epigenetic pathways can also control proliferation; recently phosophorylation of the histone $\mathrm{H} 2 \mathrm{AX}$ which was shown to limit proliferation and overall neurogenesis (Fernando et al., 2011). New neurons migrating from the RMS to the OB primarily become GABAergic granule neurons that provide lateral inhibition between mitral and tufted cells. A minority of the new neurons become periglomerular neurons that are involved in lateral inhibition between glomeruli, and a small number of these cells are dopaminergic. This differentiation is under transcriptional control and proneural basic-helix-loop-helix (bHLH) transcription factors control neuronal fate commitment in NSPCs. For example, type C cells of the SVZ fated to become GABAergic interneurons in the OB express Ascl1 (Kim et al., 2007). Ngn2 and Tbr2 are expressed in dorsal SVZ progenitors that become glutamatergic juxtaglomerular neurons (Brill et al., 2009), while Sp8 is required for parvalbumin-expressing interneurons in the $\mathrm{OB}$ (Li et al., 2011). Dopaminergic periglomerular cells in the OB express Pax6 and Dlx-2 (Doetsch et al., 2002; Hack et al., 2005; Brill et al., 2008).

\section{SGZ}

Hippocampal neurogenesis involves radial and horizontal NPCs first transitioning to intermediate progenitors and then on to immature dentate granule neurons. When the new neurons mature they make large mossy fiber projections with CA3 pyramidal neurons (Freund and Buzsaki, 1996). Sox2 has a role in maintaining the precursor pool via Sonic hedgehog (Shh) in adult SGZ and a role in proliferation of NPCs along with Pax6 and CCAAT/enhancer binding protein $\beta(\mathrm{C} / \mathrm{EBP} \beta)$ (Maekawa et al., 2005; Favaro et al., 2009; Ehm et al., 2010). Transcription factors have a large role in the differentiation of SGZ NSPCs. Neurog2 and Tbr2 are expressed in NSCs destined to become glutamatergic neurons in the hippocampus (Kim et al., 2007, 2011a; Ozen et al., 2007), while over-expression of Ascl1 produces oligodendrocytes (Jessberger et al., 2008).

Intrinsic factors are also necessary for the maturation and survival of newly born neurons. For example, Proxl (Lavado et al., 2010), NeuroD (Gao et al., 2009b; Kuwabara et al., 2009), and Kruppel-like factor 9 (Scobie et al., 2009) play important roles in survival, while cyclic response element binding protein (CREB) signaling is required for maturation and integration into the network. Interestingly, CREB activates miR-132 which regulates dendrite maturation in newborn dentate gyrus granular neurons (Magill et al., 2010). There is limited knowledge of the changes in SGZ intrinsic factors following injury; however neurogenesis is increased in the SGZ following injury. Following ischemia this increase can result from an upregulation of phosphorylated CREB (Boneva and Yamashima, 2012). In a primate model of ischemia, pro-neuronal transcription factors are expressed including Emx2, Pax6, and Ngn2 (Tonchev and Yamashima, 2006). Intriguingly, in models of neurodegeneration SGZ proliferation is decreased; as shown in a rat model of Huntington's disease, SGZ progenitor cell proliferation is decreased due to an increase in Sox2positive quiescent stem cells and a decrease in CREB signaling (Kandasamy et al., 2010).

Thus, many transcription factors have been shown to play a role in NSPC function, though few have been directly targeted by infusion of exogenous factors as a means to promote specific in vivo NSPC function and fate. Will this even be possible in vivo without genetic modification, such as by use of viral 

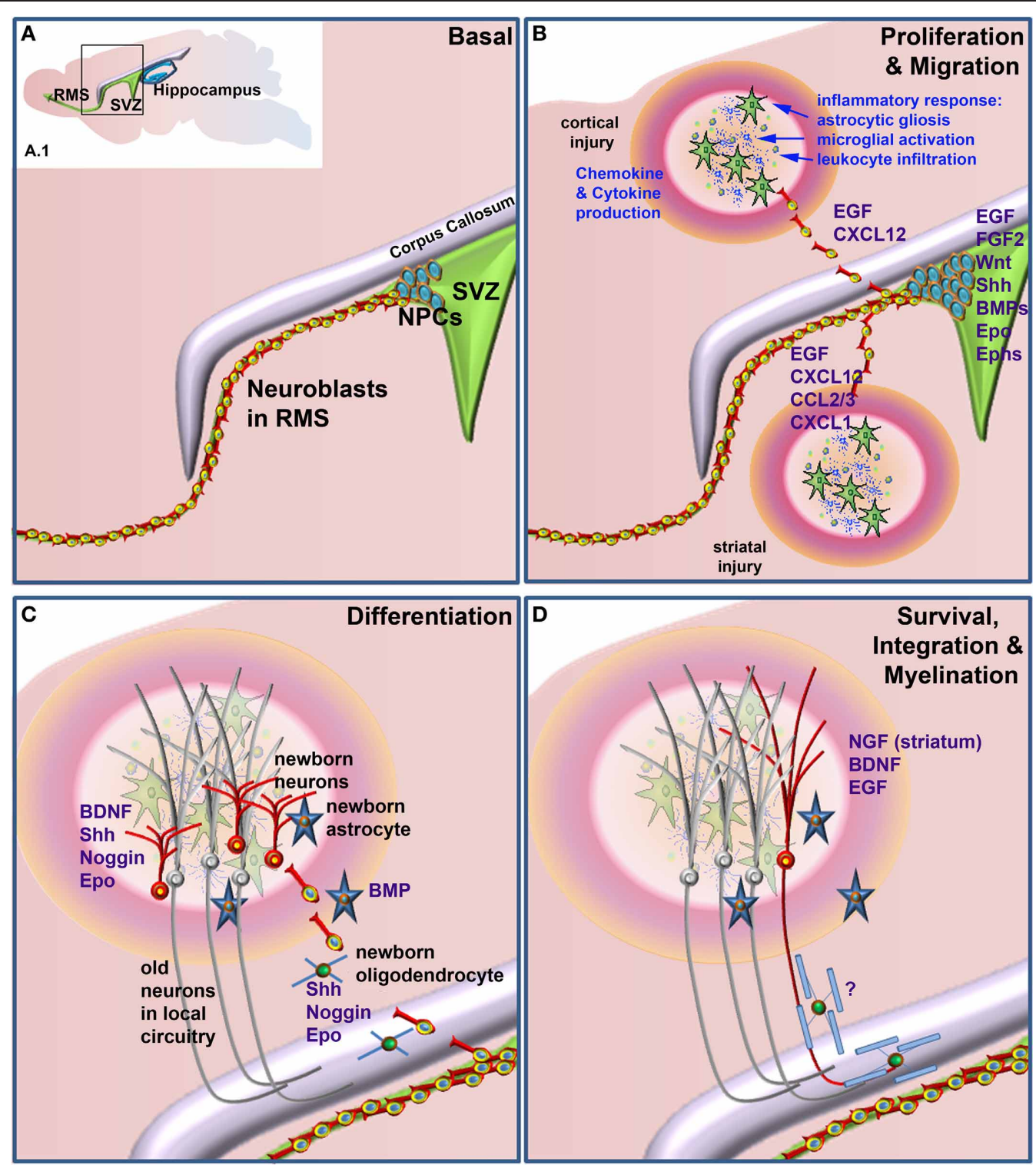

FIGURE 1 | Factors that when administered to the brain following neural damage regulate neural precursor cell responses. (A) Basal, non-damage conditions. Inset (A.1) depicts the two main neurogenic regions of the adult rodent brain, the subventricular zone (SVZ) and the hippocampus. The enlarged area bounded by the box in (A.1) depicts the general structure of the SVZ, which contains proliferative neural precursor cells (NPCs) that differentiate into neuroblasts that then migrate along the rostral migratory stream (RMS) to the olfactory bulb. Following neural injury (B) the inflammatory response induces astrocytic gliosis, microglial activation, and leukocyte infiltration from the periphery. Together, these produce a variety of chemokines, cytokines and other factors that can lead to the proliferation of the NPCS in the SVZ and redirect their migration to sites of damage. Once at or near the site of damage (C) these cells can differentiate into astrocytes, oligodendrocytes and astrocytes, depending upon which factors are administered. Unlike the normal predominance of neuronal differentiation under basal conditions, following injury SVZ NSPCs can generate neurons, astrocytes and/or oligodendrocytes. (D) Following differentiation cells need to survive and appropriately integrate into existing circuitry. This is a large bottleneck in harnessing the therapeutic potential of NSPCs, as the majority of newborn neurons die within a few weeks of their generation. For correct function, many new neurons also need to be appropriately myelinated although at present, few if any factors are known that enhance the final myelination stage of oligodendrocyte maturation following neural damage. Factors that have been shown to regulate the various stages of the NPC response when administered following neural injury are listed in blue text. expression vectors? In many cases, particular exogenous factors were chosen for in vivo examination based on their known effects on induction of desired transcription pathways in other systems. However, in most instances, only single factors have been infused. This is in contrast to work being performed in the embryonic stem (ES) cell and induced pluripotent stem (iPS) cell field, in which specific transcription factors are induced by addition of extrinsic factors for defined periods of time and in a specific sequence to allow production of desired neural cell types. For example, such a system has been used to generate floor plate 
cells which can subsequently generate mesencephalic dopaminergic neurons (Denham et al., 2012). Of course, such specific transcriptional regulation by exogenous factors is possible in the highly defined ES/iPS tissue culture environment but much more difficult in vivo, where there are many competing endogenous factors regulating NSPC function under normal conditions and even more so following neural injury. Further, the question of which transcription factors would be worth targeting for potential therapeutic effects is still open. Promoting a glial vs. a neuronal fate is relatively easy; for example infusion of BMP4 induces SMAD1/5/8 phosphorylation and subsequent astroglial fate (Cate et al., 2010). Induction of specific neuronal fates has largely not been addressed. SVZ NSPCs predominantly generate $\mathrm{OB}$ interneurons under normal conditions; however following neural injury the SVZ NSPCs can alter their normal fate, even in the absence of exogenous factor delivery, to become glial cells or adopt the specific neuronal type lost due to damage, such as striatal medium spiny neurons (Parent et al., 2002). Therefore, factors in the local damaged environment may be sufficient to direct final neuronal fate under some conditions, suggesting that adult SVZ NSPCs are not necessarily fate restricted and that defining factors to induce specific transcription factors, such as bHLH proneural genes, may be beneficial.

\section{EXTRINSIC FACTORS THAT REGULATE NSPC FUNCTION FOLLOWING NEURAL DAMAGE}

While many extracellular factors, ranging from growth factors to morphogens to extracellular matrix to cell:cell/receptor-mediated interactions have been shown to play a role in adult NSPC biology in vitro and/or in vivo, some have been more well characterized than others. This section will cover the predominant factors, as well as some less well characterized factors, shown to regulate normal adult NSPC biology and those shown to play a role following neural damage.

\section{GROWTH FACTORS}

Following ischemia and traumatic brain injury, expression of various growth factors such as epidermal growth factor (EGF), brain-derived neurotrophic factor (BDNF), nerve growth factor (NGF), fibroblast growth factor 2 (FGF2), glial cell line-derived neurotrophic factor (GDNF), insulin-like growth factor 1 (IGF-1), pituitary adenylate cyclase-activating polypeptide (PACAP), and vascular endothelial growth factor (VEGF) are increased and modulate neurogenesis and NSPC biology. Additional exogenous application further augments NSPC proliferation and sometimes survival (Watanabe et al., 2004; Baldauf and Reymann, 2005; Tureyen et al., 2005; Dempsey and Kalluri, 2007; Schabitz et al., 2007; Johanson et al., 2011; Lu et al., 2011). This section will focus on factors that have been shown to regulate NSPC responses in vivo and commence with an examination of two of the most potent mitogens for increasing numbers of NSPCs, EGF, and FGF2.

\section{EGF}

EGF is a NSPC mitogen that is commonly used to promote neurosphere growth and maintenance in cell culture (Reynolds and Weiss, 1992). Neurospheres are primarily derived from the transit-amplifying (Type C) progenitor cells in the SVZ that normally produce the neuroblasts that migrate to the OB. These cells express the EGF receptor (EGFR) and when exposed to exogenous EGF can be induced to a multi-potent state capable of generating neuronal and glial cells (Doetsch et al., 2002).

Local production of EGF in the SVZ appears to be required for normal maintenance of the proliferative NSC pool in the SVZ, and this expression is maintained by dopaminergic innervation of striatal neurons (O'Keeffe et al., 2009; O'Keeffe and Barker, 2011). Activation of dopamine receptors using the dopamine receptor agonist pramipexole (PPX) augmented neurogenesis in a PD model by upregulating expression of the EGFR (Winner et al., 2009). Furthermore, the injury-induced proliferative response of SVZ NSPCs at least partly involves upregulation of the EGFR on these cells, thus enhancing their responsiveness to EGF (Alagappan et al., 2009). However, transforming growth factor alpha $(\mathrm{TGF} \alpha)$, which also binds to the EGFR, is expressed at higher levels in the adult brain than EGF (Seroogy et al., 1993) and so TGF $\alpha$ may be the normal ligand for regulating NSPC function in vivo.

Given the mitogenic properties of EGF for NSPCs, infusion of EGF into the lateral ventricles following neural damage has been used to increase proliferation of NSPCs and attempt to increase their contribution to neural repair. This has led to mixed results, depending upon the injury/disease model used and possibly the species in which it was examined. EGF infusion for 6 days into the normal adult mouse forebrain increased the number of NSPCs at the SVZ, promoted their migration into the parenchyma (cortex, striatum, and septum), and resulted in $25 \%$ surviving for at least 7 weeks; however the majority of cells that differentiated were astrocytes with a small percentage of neurons and oligodendrocytes (Craig et al., 1996). Indeed, generally, EGF tends to promote an astroglial rather than neuronal fate, at least in rats (Kuhn et al., 1997). However, in mice, infusion of EGF into the lateral ventricles of the uninjured brain similarly increased SVZ NSPC proliferation and induced their migration into surrounding parenchyma, but most of the cells adopted an oligodendroglial fate, with a smaller percentage astroglial. This was further enhanced following a demyelinating lesion of the corpus callosum (Gonzalez-Perez et al., 2009). These cells may be a sub-population of SVZ NSPCs, the NG2+ oligodendrocyte progenitors, which express EGFR and are induced to migrate in response to EGF (Aguirre et al., 2005, 2007).

Conversely, in the damaged brain, such as following ischemia, EGF promoted SVZ NPC proliferation with subsequent production of neuroblasts in SVZ and striatum (Ninomiya et al., 2006), also it induced migration of doublecortin positive precursors and their subsequent long term (13 weeks) survival as parvalbumin-expressing interneurons (Teramoto et al., 2003). A similar infusion following traumatic brain injury also induced SVZ proliferation, as well as SGZ proliferation, at early timepoints but did not promote longer term (4 weeks survival) of the newborn SGZ cells, many of which had differentiated into astrocytes rather than neurons (Sun et al., 2010). Similarly, in a rat model of ischemia EGF alone induced proliferation and some NSPC migration but did not promote regeneration unless combined with a later administration of erythropoietin (Epo) (Kolb 
et al., 2007), with similar results obtained for infusion of TGF $\alpha$ in a PD model (Cooper and Isacson, 2004). Part of the discrepancy between differentiation outcomes may lie in rat:mouse species differences. In general, mouse studies have indicated that EGF infusion can promote proliferation, migration and at least some neuronal differentiation while rat studies have shown proliferation, some migration and differentiation into glial cells, if they are found to differentiate at all. This may be due to EGF-induced dysplasia in rat but not mouse SVZ (Lindberg et al., 2012). In rats, the EGF-induced NSPC proliferative response generates SVZ/lateral ventricle polyps, which contain a higher percentage of cells expressing the transcription factors Sox2, Olig2, markers of proliferative NPCs, as well as Id1, an inhibitor of neuronal differentiation, concomitant with decreased expression of the neuroblast marker doublecortin. This suggests that in rat, EGF promotes proliferation of more glial fated NPCs that do not migrate to the same extent as mouse NPCs exposed to EGF. However, combination of EGF plus other growth factors appears to overcome some of the limitations of infusion of EGF alone to some extent.

\section{EGF plus FGF2}

FGF2 is another potent NSPC mitogen, commonly used to induce proliferation of these cells in culture, usually in combination with EGF. Infusion of FGF2 by itself into the lateral ventricles of normal adult rats promotes NSPC proliferation and enhances neurogenesis in the OB (Kuhn et al., 1997). Following traumatic brain injury it has been shown to enhance SVZ and SGZ NSPC proliferation and increase the 4 weeks survival of newborn neurons (Sun et al., 2009), while FGF2 knockout mice show decreased hippocampal neurogenesis following seizure or ischemia (Yoshimura et al., 2001). In addition, conditional deletion of FGFR1, the major receptor for FGF2, decreases hippocampal neurogenesis and impairs memory consolidation (Zhao et al., 2007). Quite a few studies have used a combination of EGF and FGF2 infusion, which has generally promoted neural repair. In a rat global ischemia model, which led to loss of CA1 hippocampal neurons, EGF+FGF2 promoted proliferation of SVZderived cells which repopulated the damaged CA1 hippocampal neurons and promoted functional recovery (Nakatomi et al., 2002). Similar studies reported increased numbers of neural progenitors in hippocampus, as well as SVZ and hypothalamus (Oya et al., 2008). Comparable results were obtained following transient middle cerebral artery occlusion in rat, including increased neuronal numbers and survival (Tureyen et al., 2005). However, in an endothelin model of transient ischemia, while co-infusion of EGF+FGF2 promoted increases in SVZ neurogenesis, it decreased hippocampal neurogenesis and increased infarct volumes (Baldauf and Reymann, 2005) but the reasons for the different outcomes in these models is not clear. Increased proliferation and migration to dopamine deficient areas have also been observed following EGF+FGF2 infusion in a PD model (Winner et al., 2008).

\section{Other factors that can promote NSPC proliferation}

Although EGF and FGF2 are possibly the most potent NSPC mitogens, particularly for SVZ-derived cells, other factors can also promote increases in NSPC numbers, although most have yet to be tested in brain injury/disease models. Infusion of ATP into the lateral ventricles of mice increased numbers of transit amplifying progenitor cells (Suyama et al., 2012). A mechanism by which this occurs may involve induction of FGF2 and TGF synthesis (Jia et al., 2011). VEGF can augment SVZ progenitor proliferation, as well as migration (Wittko et al., 2009; Calvo et al., 2011). Other factors have been shown to enhance proliferation induced by EGF and/or FGF2 without having a notable effect by themselves, such as growth hormone (GH) (McLenachan et al., 2009).

IGFs also play a role in several NSPC functions. IGF1 has different effects in the SVZ and dentate gyrus SGZ. Peripheral administration promotes hippocampal dentate gyrus NSPC proliferation and increases subsequent dentate gyrus neurogenesis (Aberg et al., 2000) and survival (Cheng et al., 2001). GH receptor knockout mice, which are serum-IGF1-deficient, do not show any alterations in hippocampal neurogenesis (Ransome and Turnley, 2008b), which may indicate that local hippocampal/dentate gyrus production of IGF-1 is important in supporting ongoing hippocampal neurogenesis (Sun et al., 2005a). However, peripheral administration of GH promoted hippocampal but not SVZ NSPC proliferation (Aberg et al., 2009). Indeed, in the SVZ IGF1 does not seem to regulate proliferation, rather being more important for NSPC migration; IGF1 null mice show an abundance of neuroblasts in the SVZ that have failed to migrate to the $\mathrm{OB}$ (Hurtado-Chong et al., 2009). IGF2 regulates proliferation in the dentate gyrus in an Akt-dependent manner (Bracko et al., 2012) and promotes survival of newborn hippocampal neurons as well as regulating hippocampal dependent fear extinction (Agis-Balboa et al., 2011).

\section{NEUROTROPHINS}

Neurotrophin signaling mediated by BDNF interacting with TrkB receptors and to a much lesser extent NGF binding to TrkA, regulates several aspects of NSPC function. In the adult brain, TrkB expression and effects of BDNF are widespread but TrkA expression is very limited, primarily restricted to basal forebrain cholinergic neurons which project to the NGF-expressing hippocampus. Therefore, effects of BDNF in NSPC biology have been the most widely studied, although NGF infusion has been shown to promote the survival of normal newborn dentate granule cell neurons but not proliferation of their progenitors (Frielingsdorf et al., 2007). Intranasal delivery of NGF following focal ischemia in rats similarly did not promote proliferation of SVZ progenitors but enhanced subsequent newborn neuronal survival in the ipsilateral SVZ and injured striatum (Zhu et al., 2011).

In vitro, SVZ-derived neurospheres express TrkB and little/no TrkA or TrkC and addition of BDNF promoted a transient increase in newborn neuron numbers due to enhanced differentiation and neurite outgrowth, rather than a proliferative effect on the NSPCs (Ahmed et al., 1995). Further, BDNF is required for cultured hippocampal progenitor cells to adopt a neuronal fate (Bull and Bartlett, 2005).

In the dentate gyrus, $\operatorname{TrkB}$ is expressed predominantly by maturing but not proliferating neuroblasts (Donovan et al., 2008), which correlates with findings that BDNF is important for neuroblast migration, survival, and integration of new neurons. BDNF increases the number and survival of newborn neurons 
in the SVZ and OB (Kirschenbaum and Goldman, 1995; Zigova et al., 1998; Bath et al., 2008), in a p75 neurotrophin receptordependent manner (Young et al., 2007), and in striatum, caudate putamen and septum (Benraiss et al., 2001; Henry et al., 2007), dentate gyrus (Lee et al., 2002) as well as subcallosal neurons (Kim et al., 2011b). Knockdown of TrkB receptors and disruption of BDNF signaling resulted in decreased SGZ NSPC proliferation and neurogenesis, indicating that $\operatorname{TrkB}$ signaling may also have some proliferative effects in these cells (Li et al., 2008). Disruption of BDNF signaling also results in shorter dendrites and reduced spine formation, culminating in a lack of survival of newborn granule cells (Bergami et al., 2008; Gao et al., 2009a). In addition, conditional deletion of BDNF resulted in increased death of newborn neurons in mice following traumatic brain injury (Gao and Chen, 2009). However, conversely, enhanced long-term AAVmediated BDNF expression in the hippocampus was shown to inhibit neurogenesis following ischemia in rats (Larsson et al., 2002). The reason for this discrepancy is unclear and further work is required to delineate the mechanisms by which BDNF regulates adult neurogenesis following neural damage. Given that neural activity promotes BDNF-mediated TrkB activation (Aloyz et al., 1999) and TrkB signaling is required for activity-dependent differentiation of hippocampal NSPCs, BDNF is likely to be a critical factor to promote NSPC-derived newborn neuron survival and integration into neural circuitry. However, if too much BDNF-stimulation is provided, this may be at the expense of NSPC numbers in some situations but this needs further study for confirmation.

BDNF combined with a mitogen is more effective in enhancing NSPC function and may be a better therapeutic option. Neurogenic NSPCs can be cultured from SVZ of adult humans but requires a combination of FGF2 and BDNF for robust growth (Pincus et al., 1998). This combination also appears to be required for creating a neurogenic environment in normally non-neurogenic regions in vivo (Chen et al., 2007a). In addition, co-infusion of BDNF plus EGF was more effective than either factor alone at promoting long term striatal neuron survival following ischemic injury in mice (Im et al., 2010).

\section{MORPHOGENS}

The morphogens Wnt, Shh, and Bone Morphogenic Proteins (BMPs) play a major role in neural development with some data to suggest they may also play a role in the NSPC response to neural damage.

\section{Wnt signaling}

While Wnts are endogenously expressed in adult neurogenic niches (Wexler et al., 2009), their expression is not upregulated following neuronal damage, such as stroke (Morris et al., 2007). Wnt signaling via $\beta$-catenin, promotes NSC proliferation to regulate their maintenance (Lie et al., 2005; Adachi et al., 2007). This appears to be by regulating symmetric vs. asymmetric division, promoting symmetric division during neural regeneration (Piccin and Morshead, 2011). Wnt signaling is negatively regulated by glycogen synthase kinase 3 beta (GSK3 $\beta$ ) and inhibitors of GSK3 $\beta$ have been proposed as candidate targets for neural repair (Mao et al., 2009). Inhibition of $\beta$-catenin signaling by the amyloid beta peptide resulted in reduced neurogenesis from NPCs grown from Alzheimer disease brains, which also have increased levels of GSK3 $\beta$ (He and Shen, 2009). Further, downregulation of $\beta$-catenin in a rat stroke model inhibited striatal neurogenesis (Lei et al., 2008), while overexpression of Wnt3a following focal ischemia promoted NSPC proliferation, neurogenesis and functional recovery (Shruster et al., 2012). However, following traumatic brain injury in mice, $\beta$-catenin activity was upregulated in cortical NG2+ oligodendrocyte/astrocyte progenitor cells, suggesting that it also plays a role in gliogenesis following injury (White et al., 2010).

\section{Shh}

Intrathecal administration of Shh to rats following ischemia promoted SVZ NSPC proliferation and improved behavioral recovery (Bambakidis et al., 2012), while following spinal cord injury it promoted proliferation of nestin+ NSPCs surrounding the central canal leading to increased numbers of oligodendrocyte precursors and neurons (Bambakidis et al., 2003). Shh expression is upregulated in the SVZ and hippocampus following ischemia, potentially playing a role in increased proliferation in a Notch dependent manner (Sims et al., 2009; Wang et al., 2009); however in the hippocampus its expression was also upregulated in mature CA3 neurons, suggesting effects in mature neurons as well as progenitors (Sims et al., 2009). The source of Shh in the adult brain appears to be astrocytes. In the normal brain, astrocytes in neurogenic regions produce Shh and when transplanted they induce neurogenesis in non-neurogenic regions of the brain, such as cortex (Jiao and Chen, 2008). Following brain injury activated astrocytes upregulate Shh expression in response to pro-inflammatory stimuli, which subsequently promotes increased numbers of Olig2+ NSPCs (Amankulor et al., 2009); this may be via activation of quiescent endogenous cortical NSPCs derived from astrocytes (Ahmed et al., 2012). However, in different neuroinflammatory conditions, such as experimental allergic encephalomyelitis (EAE) or multiple sclerosis, the inflammatory response induces Shh in astrocytes as above but inhibits Shh-induced NSPC differentiation by subsequent downregulation of the Glil transcription factor (Wang et al., 2008).

\section{Bone morphogenic proteins (BMPs)}

The role of BMP signaling in NSPCs and their role following CNS injury has recently been reviewed (Sabo et al., 2009) and so will only be covered briefly here. In general, BMP signaling inhibits neuronal and oligodendroglial differentiation of NPCs and promotes astrogliogenesis, during development (Gross et al., 1996) and in the adult (Lim et al., 2000), with somewhat different effects at different stages of development (Mehler et al., 2000). However, expression of the BMP inhibitor noggin in the SVZ (Lim et al., 2000) or SGZ (Bonaguidi et al., 2008) can obstruct this cascade and promote neurogenesis. Further, BMP signaling promotes non-neurogenic parenchymal astroglial cell fate while leukemia inhibitory factor (LIF), which also promotes astrogliogenesis, promotes cells of an astroglial progenitor cell phenotype (Bonaguidi et al., 2005). Demyelination induced expression of the BMP antagonist chordin in the SVZ, induced glial fate in neuroblasts to generate new oligodendrocytes in the corpus callosum 
(Jablonska et al., 2010). Conversely, BMP signaling in SVZ NSCs but not NPCs is required to promote a neurogenic rather than oligodendrogliogenic cell fate (Colak et al., 2008).

BMP signaling inhibits NPC proliferation (Gajera et al., 2010) and while inhibition of the BMP pathway increases neurogenesis initially, it eventually results in depletion of the NSC pool, leading to decreased neurogenesis in the dentate gyrus (Mira et al., 2010). This indicates that a fine balance of BMP signaling vs. inhibition is required to regulate appropriate NSC numbers and subsequent cell fate.

Given that BMP signaling promotes an astroglial fate and inhibits oligodendrogliogenesis and neurogenesis, the effect of inhibition of BMP signaling by infusion of noggin into the lateral ventricles has been examined in various models of neural injury. In cuprizone-induced demyelination models noggin infusion inhibited the cuprizone induced upregulation of BMP4 and its signaling pathways, decreased SVZ astrocyte numbers, increased oligodendrocyte numbers and promoted remyelination of the corpus callosum (Cate et al., 2010; Sabo et al., 2011), possibly by regulation of Olig2 function (Chen et al., 2012). Noggin infusion also produced similar results in a model of intraventricular hemorrhage (Dummula et al., 2011). In a brain injury model, noggin was found to be produced by reactive astrocytes and similarly promoted oligodendrocyte fate (Hampton et al., 2007). It was also recently shown that $\mathrm{Bcl} 2$ regulates neurogenesis in a striatal injury model, by increasing $\beta$-catenin expression and decreasing BMP4 expression, in a noggin independent fashion (Lei et al., 2012).

\section{ERYTHROPOIETIN (Epo)}

Epo is a cytokine better known for its regulation of erythrocyte production. However it also has a number of functions within the CNS and on NSPC biology. Epo is expressed in the developing and adult SVZ (Shingo et al., 2001) and is required for endogenous embryonic and adult SVZ and SGZ neurogenesis (Tsai et al., 2006; Chen et al., 2007b). It promotes neurogenesis of SVZ NSPCs at the expense of multipotent progenitors in the normal rodent brain (Shingo et al., 2001) but in the SGZ this effect is transient, briefly increasing neuronal progenitor numbers but with no long term enhancement of survival (Ransome and Turnley, 2007). One of the mechanisms by which it may do this is by upregulation of Suppressor of Cytokine Signaling-2 (SOCS2) in NSPCs (Wang et al., 2004b). SOCS2, an intracellular regulator of cytokine signaling, promotes embryonic SVZ neurogenesis (Turnley et al., 2002; Scott et al., 2006), while in the hippocampus it promotes NSPC-derived newborn neuron survival (Ransome and Turnley, 2008b). It also promotes axonal growth of hippocampal neurons (Ransome and Turnley, 2008a), which may be a factor contributing to its enhanced neuroprotective effects following neural injury.

Following neural damage Epo has been found to be both neuroprotective and to promote neurogenesis (Wang et al., 2004a). Epo expression is induced/upregulated by hypoxia and thus many studies have examined its role post-ischemia or in ischemia/hypoxia models, although it has also been shown to be effective following traumatic brain injury. Conditional knockdown of the Epo receptor reduced post-stroke neurogenesis, with reduced proliferation and stroke-induced neuroblast migration to the cortex (Tsai et al., 2006). The Epo-induced NSPC migration appears to be indirect, rather inducing expression of matrix metalloproteases in endothelial cells, which in turn induced NSPC migration (Wang et al., 2006). Peripheral administration of Epo promotes NSPC proliferation, neurogenesis, oligodendrogenesis, and neurovascular remodeling following traumatic brain injury in rats, enhancing functional outcome ( $\mathrm{Lu}$ et al., 2005; Zhang et al., 2010; Meng et al., 2011; Ning et al., 2011; Xiong et al., 2011). Inhibition of proliferation by infusion of $\mathrm{AraC}$ into the ventricles inhibited Epo-induced dentate gyrus neurogenesis and recovery of spatial learning (Zhang et al., 2012). Epo has also been shown to be neuroprotective in disease models, such as $\mathrm{PD}$, in which it promoted SVZ NSPC proliferation and migration to the damaged striatum (Kadota et al., 2009).

One of the problems associated with use of Epo as a therapeutic for promotion of neural regeneration is that it generally increases the hematocrit at doses required for promotion of neurogenesis (e.g., $5000 \mathrm{U} / \mathrm{kg}$ ). While this has not presented major issues for use in animal models, it raises concerns for potential clinical use. Therefore, several Epo derivatives have been developed to try to promote neuroprotective effects while avoiding effects on erythrocyte production. Carbamylated Epo does not bind to classical Epo receptor and does not stimulate erythropoiesis but does promote SVZ and dentate gyrus proliferation and neuronal differentiation of adult NSPCs (Wang et al., 2007; Leconte et al., 2011), while a different non-erythropoietic derivative asialo-Epo promoted SVZ-derived oligodendrogenesis (Kako et al., 2012). A peptide agonist of Epo, Epobis, has also recently been developed and shown to promote neuron survival and neurite outgrowth, but its effects on neurogenesis have yet to be determined (Pankratova et al., 2012).

\section{CHEMOKINES AND CYTOKINES}

Chemokines form a family of small $(8-14 \mathrm{kD})$, mainly basic, secreted molecules that are primarily known for regulating chemoattraction of immune cells to sites of tissue damage. They have been reported to have widespread non-immunological effects in the CNS, including regulation of neural cell proliferation, migration, survival, and synaptic transmission and can act in a paracrine or autocrine manner (Bajetto et al., 2002; Cartier et al., 2005).

Pro-inflammatory cytokines, such as interferon gamma $(\mathrm{IFN} \gamma)$ and tumor necrosis factor alpha (TNF $\alpha)$ appear to be major regulators of chemokine and chemokine receptor expression in many tissues (Hiroi and Ohmori, 2003; Suyama et al., 2005). In the adult brain there is basal expression of chemokines, especially in neurogenic regions, while treatment with IFN $\gamma$ and TNF $\alpha$ can significantly increase the expression of specific chemokines including CXCL1, CXCL9, and CCL2 (Turbic et al., 2011).

Adult NSPCs express a range of chemokine receptors and chemokines are expressed in different brain regions, with the highest levels in the OB, suggesting an as yet largely unexplored role for chemokines in regulating basal adult NPC migration (Turbic et al., 2011). Neurospheres derived from adult mouse SVZ-derived NPCs have been shown to express a range 
of chemokine receptors, including CCR1-8, 10 and CXCR1-6 (Tran et al., 2004). Functionally, specific chemokines, such as CXCL12/CXCR4 can promote NPC migration (Imitola et al., 2004; Tran et al., 2004; Dziembowska et al., 2005) and proliferation (Tran et al., 2004) or survival (Krathwohl and Kaiser, 2004; Dziembowska et al., 2005) in vitro. Following neural damage, NPC migration to site of injury is promoted by CXCL12 (Imitola et al., 2004; Itoh et al., 2009) and is mediated at least in part, by induction of metalloprotease expression in the NPCs (Barkho et al., 2008). CCL2, CCL3, and CXCL1 also promote NPC migration to striatum following quinolinic acid lesion (Gordon et al., 2009).

The gp130-associated cytokines, ciliary neurotrophic factor (CNTF) and leukemia inhibitory factor (LIF), activate Janus kinase [JAK/signal transducer of transcription 3 (STAT3)], mitogen activated protein (MAP) kinase and PI-3K/Akt pathways following ligand binding. These cytokines have been shown to regulate NSC proliferation and differentiation (Turnley and Bartlett, 2000; Heinrich et al., 2003; Kamimura et al., 2003; Ernst and Jenkins, 2004). IFN $\gamma$, which signals via STAT1, and IFN $\beta$ which does not, both inhibit cultured adult NPC proliferation, but only IFN $\gamma$ promotes neuronal differentiation (Wong et al., 2004; Lum et al., 2009). Specifically in the dentate gyrus, the activation of STAT3 from CNTF appears to be essential for the formation and maintenance of the NSCs (Muller et al., 2009).

\section{OTHER FACTORS THAT PLAY A ROLE IN NSPC FUNCTION THAT MAY BE TARGETED FOR NEURAL REPAIR}

There are factors involved in neurogenesis other than extrinsic growth factors and cytokines, as discussed above. Some of these include membrane bound molecules, neurotransmitters and their receptors and blood vasculature.

\section{EPH/EPHRIN SIGNALING AND NSPCs-A NEW TARGET TO PROMOTE NSPC PROLIFERATION, SURVIVAL, AND MIGRATION}

The Eph family of receptor tyrosine kinases and their ligands, the ephrins, are membrane bound molecules that signal bidirectionally, are generally involved in cell or axon guidance by repulsive mechanisms and which play a role following neural injury (reviewed in Goldshmit et al., 2006b). They have been receiving increasing interest of late as they have been shown to play major roles in inhibition of regeneration in the CNS following neural injury or disease, with deletion or blocking of various Ephs or ephrins promoting neural repair (Goldshmit et al., 2004, 2006b, 2011; Rodger et al., 2004; Liu et al., 2006; Fabes et al., 2007; Overman et al., 2012; Van Hoecke et al., 2012). EphA4 also plays a role in regulation of inflammation following neural injury (Munro et al., 2012), which could have secondary effects on NSPC responses.

Eph receptor signaling also regulates several aspects of NSPC biology but as yet has not been targeted to enhance NSPC responses following injury. The EphB2/ephrin-B2 pathway enables formation of the chain migration from the SVZ to the OB (Conover et al., 2000) and also controls the conversion of ependymal cells to astrocytic NSPCs (Nomura et al., 2010). EphB2 signaling via ephrin-B1 is also required for development of the dorsal half of the dentate gyrus, where it controls migration of the dentate progenitor cells (Catchpole and Henkemeyer, 2011). Ephrin-A2 signaling via EphA7 inhibits SVZ NSPC proliferation and subsequent neurogenesis (Holmberg et al., 2005), while conversely ephrin-A5 signaling via EphA7 induces their apoptosis (Depaepe et al., 2005). EphB2 and ephrin-B signaling however promotes SVZ NSPC proliferation, decreases migration, and promotes neuronal differentiation (Katakowski et al., 2005), with ephrin-B1 expression in SVZ NSPCs critical for maintenance of the proliferative NSPC state (Qiu et al., 2008), a role also played by EphA4 (Khodosevich et al., 2011). In addition, EphB3 is expressed by adult SVZ NSPCs and neuroblasts and EphB3 and ephrin-B3 knockout mice show increased neonatal and adult SVZ NSPC proliferation, indicating that this pathway normally inhibits their proliferation (Theus et al., 2010; Del Valle et al., 2011; Doeppner et al., 2011). Infusion of soluble ephrin-B3 into the lateral ventricles reversed the proliferation defect in ephrinB3 knockout mice but not the EphB3 receptor knockout mice (Theus et al., 2010).

In the hippocampus, EphB1 and ephrin-B3 promote hippocampal NSPC proliferation and migration, as well as cell polarity (Chumley et al., 2007), while ephrin-A5 promotes hippocampal NSPC proliferation and neurogenesis, at least partly through regulation of the normal vascular system (Hara et al., 2010), which requires normal EphA4 (Goldshmit et al., 2006a) and EphB4 signaling (Colin-Castelan et al., 2011). Ephrin-B2, expressed by hippocampal astrocytes in the SGZ, induces neuronal differentiation of EphB4-expressing hippocampal NSPCs and this effect involves activation of $\beta$-catenin independent of Wnt signaling, with subsequent upregulation of proneural transcription factors (Ashton et al., 2012).

To date, little has been examined regarding the role of Eph/ephrin signaling following neural damage. Following traumatic brain injury, EphB3 expression was transiently downregulated, which may lift its inhibition of NSPC proliferation and this may be one of the mechanisms by which NSPCs are able to respond to injury, by increasing proliferation and survival (Theus et al., 2010). However, in ephrin-B3 knockout mice, while there was an increase in NSPC proliferation following ischemic injury, there was also enhanced cortical damage with an increased infarct volume (Doeppner et al., 2011) due to NSPCindependent effects of ephrin-B3, which will need to be taken into account when considering therapeutic use of Eph/ephrins. Conversely, in a model of PD infusion of soluble ephrin-A1 into the lateral ventricles, to activate EphA receptor/s, promoted SVZ NSPC proliferation and migration of these cells to striatum, where they subsequently differentiated in dopaminergic neurons (Jing et al., 2012).

\section{OTHER FACTORS}

Following injury, one of the early mediators of the injury response is upregulation of nitric oxide (NO). NO has been reported to have proliferative (Zhang et al., 2001a; Reif et al., 2004) or anti-proliferative (Packer et al., 2003; Park et al., 2003; MorenoLopez et al., 2004) effects on basal SVZ and SGZ NSPCs, as well as following injury (Zhang et al., 2001a; Zhu et al., 2003; Sun et al., 2005b). This apparent discrepancy in effect appears to lie largely in the source of NO production and the 
subsequent signaling pathways induced. If the NO derives from neuronal nitric oxide synthase (nNOS) then the effect is largely anti-proliferative (Packer et al., 2003; Moreno-Lopez et al., 2004; Sun et al., 2005b), but if derived from inducible NOS (iNOS) (Zhu et al., 2003; Carreira et al., 2010) or endothelial derived NOS (eNOS) (Reif et al., 2004) then the effects are largely proliferative. This likely relates to the location of NOS as well as the concentration of NO produced. Further, infusion of NO donors that induce MAP kinase signaling (Carreira et al., 2010) or cyclic guanosine monophosphate (cGMP) signaling, promotes proliferation and neurogenesis in normal and ischemic rats (Zhang et al., 2001a). Indeed, both pathways appear to be involved in NSPC proliferation in response to NO, with activation of the MAPK pathway at shorter timepoints $(6 \mathrm{~h})$ and activation of cGMP at later timepoints ( $24 \mathrm{~h}$ ) (Carreira et al., 2012). Recent work has indicated that the NO-cGMP pathway is also an important mediator of the neuro-proliferative effects of other factors, such as Neuropeptide $\mathrm{Y}$ in the hippocampus (Howell et al., 2005; Agasse et al., 2008; Cheung et al., 2012) and also explains the increased proliferation and neurogenesis observed with infusion of phosphodiesterase inhibitors, such as sildenafil and tadalafil, which lead to increased cGMP levels and improve outcome in stroke models (Zhang et al., 2003, 2006). cGMP levels also appear to regulate NSPC fate during embryonic development, with high levels promoting neuronal differentiation and low levels non-neuronal fate (Gomez-Pinedo et al., 2010), however, whether this is the case in adult remains to be determined.

Endocannabinoid signaling has been shown to regulate migration and neurogenesis in both the SVZ and dentate gyrus (Aguado et al., 2005, 2007; Jiang et al., 2005; Goncalves et al., 2008; Gao et al., 2010; Hill et al., 2010; Wolf et al., 2010; Oudin et al., 2011a,b). Other molecules involved in NPC migration include polysialated neural cell adhesion molecule (PSA-NCAM) (Cremer et al., 1994; Hu et al., 1996; Chazal et al., 2000), SlitRobo (Wu et al., 1999), and integrins (Jacques et al., 1998; Murase and Horwitz, 2002). In basal conditions, reelin is a detachment signal for neuroblasts from the RMS at the OB (Hack et al., 2002), while overexpression of reelin in a demyelinating lesion led to an increase in ectopic migration of neuroblasts at the lesion site (Courtes et al., 2011). Many of these factors signal via the Rho kinase pathway, which is a downstream regulator of NPC migration (Leong et al., 2011) and targeting this pathway may circumvent the large number of external signals that converge on this pathway to allow more precise control of directed NPC migration and possibly neuronal differentiation and survival. In the brain parenchyma NSPCs interact with blood vessels in the neurovascular niche (Shen et al., 2008; Tavazoie et al., 2008), neuroblasts can migrate along blood vessels (Honda et al., 2007) and use vessels to migrate radially into the cortex (Le Magueresse et al., 2012). Following ischemia SVZ neuroblasts migrate to the infarct in close association with blood vessels (Ohab et al., 2006; Yamashita et al., 2006; Thored et al., 2007; Kojima et al., 2010).

NMDA receptors expressed in neuroblasts along the RMS are crucial to the integration of these neurons in existing OB circuitry (Platel et al., 2010), with glutamate released from astroglial cells in the glial tube that surrounds the migrating neuroblasts. NMDA receptor activation in newly born dentate gyrus granule cells also increases survival. Initial GABA depolarization promotes maturation of neurons in the dentate gyrus and OB (Saghatelyan et al., 2005; Ge et al., 2006) and this depolarization and subsequent $\mathrm{Ca}^{2+}$ influx are required for dendrite initiation and elongation (Gascon et al., 2006). Agrin signaling is also necessary for integration and survival of newborn neurons in the OB: a loss of agrin leads to improper synapse formation while overexpression of agrin results in an increase in dendritic spines (Burk et al., 2012).

The migration distance for new neurons from the SGZ is relatively short as they travel into the granular layer above the SGZ, where guidance molecules may control this movement. NMDA receptor signaling is required for the proper migration of newborn granular cells in the dentate gyrus (Namba et al., 2011). This is achieved through the activation of Disrupted-in-schizophrenia (DISC1), as neurons without DISC1 migrate further into granular layer and into the molecular layer (Duan et al., 2007; Namba et al., 2011). DISC1 also controls the dendritic maturation of newborn granule cells through GABA depolarization of NKCC1 and activation of the Akt-mTOR pathway (Duan et al., 2007; Kim et al., 2012), while Reelin regulates migration and dendritic development of adult-generated hippocampal neurons (Teixeira et al., 2012). Whether targeting any of the above factors will enhance NSPC responses following neural injury largely remains to be determined.

\section{CONCLUSIONS}

Many factors regulate the biology of NSPCs at different stages along their growth and maturation cycle. To date, the majority of studies which have administered extrinsic growth factors or cytokines have concentrated on the effect of a single factor at a time. However, some studies are now emerging where combinatorial effects of different factors have been examined. It will not be sufficient to only increase the number of NSPCs produced by administration of a mitogen. While this can indeed increase neurogenesis, the number of surviving and functionally integrated neurons (or oligodendrocytes) is still very limited. It would be prudent to combine use of mitogens with other factors that enhance neurogenesis or oligogliogenesis respectively, as well as factors that enhance their subsequent survival and integration. Which factors are chosen to combine will likely depend on the injury or disease model to be examined, whether neurons and/or oligodendrocytes need to be replaced and may also be species dependent to a certain extent, although the combination of a mitogen such as EGF and a survival factor, such as BDNF may be generally beneficial. Some factors, such as Epo, have multiple actions, including NSPC proliferation, neuronal differentiation, and oligodendrocyte maturation, as well as being neuroprotective, which makes them particularly attractive as potential therapeutics for treatment of the damaged brain. Most of the work described above was conducted in rodents and to date little work has been performed following neural injury in brains of gyrencephalic species, such as non-human primates (Tonchev et al., 2003a,b, 2005, 2007). Sheep models are also being developed to allow such questions to be answered in a model 
more relevant to human brain damage (e.g., Wells et al., 2012). Human clinical trials are also underway to test therapeutic effectiveness of a range of extrinsic factors, such as Epo, following brain injury. For a complete list see www.clinicaltrials.gov. Two decades since their discovery in mammalian brains, facilitation of the NSPC response to brain damage by administration of

\section{REFERENCES}

Aberg, M. A., Aberg, N. D., Hedbacker, H., Oscarsson, J., and Eriksson, P. S. (2000). Peripheral infusion of IGF-I selectively induces neurogenesis in the adult rat hippocampus. J. Neurosci. 20, 2896-2903.

Aberg, N. D., Johansson, I., Aberg, M. A., Lind, J., Johansson, U. E., Cooper-Kuhn, C. M., et al. (2009). Peripheral administration of GH induces cell proliferation in the brain of adult hypophysectomized rats. J. Endocrinol. 201, 141-150.

Adachi, K., Mirzadeh, Z., Sakaguchi, M., Yamashita, T., Nikolcheva, T., Gotoh, Y., et al. (2007). Beta-catenin signaling promotes proliferation of progenitor cells in the adult mouse subventricular zone. Stem Cells 25, 2827-2836.

Agasse, F., Bernardino, L., Kristiansen, H., Christiansen, S. H., Ferreira, R., Silva, B., et al. (2008). Neuropeptide $\mathrm{Y}$ promotes neurogenesis in murine subventricular zone. Stem Cells 26, 1636-1645.

Agis-Balboa, R. C., Arcos-Diaz, D., Wittnam, J., Govindarajan, N., Blom, K., Burkhardt, S., et al. (2011). A hippocampal insulingrowth factor 2 pathway regulates the extinction of fear memories. EMBO J. 30, 4071-4083.

Aguado, T., Monory, K., Palazuelos, J., Stella, N., Cravatt, B., Lutz, B., et al. (2005). The endocannabinoid system drives neural progenitor proliferation. FASEB J. 19, 1704-1706.

Aguado, T., Romero, E., Monory, K., Palazuelos, J., Sendtner, M., Marsicano, G., et al. (2007). The CB1 cannabinoid receptor mediates excitotoxicity-induced neural progenitor proliferation and neurogenesis. J. Biol. Chem. 282, 23892-23898.

Aguirre, A., Dupree, J. L., Mangin, J. M., and Gallo, V. (2007). A functional role for EGFR signaling in myelination and remyelination. Nat. Neurosci. 10, 990-1002.

Aguirre, A., Rizvi, T. A., Ratner, N., and Gallo, V. (2005). Overexpression of the epidermal growth factor receptor confers migratory properties to nonmigratory postnatal neural progenitors. J. Neurosci. 25, 11092-11106.
Ahmed, A. I., Shtaya, A. B., Zaben, M. J., Owens, E. V., Kiecker, C., and Gray, W. P. (2012). Endogenous GFAP-positive neural stem/progenitor cells in the postnatal mouse cortex are activated following traumatic brain injury. J. Neurotrauma 29, 828-842.

Ahmed, S., Reynolds, B. A., and Weiss, S. (1995). BDNF enhances the differentiation but not the survival of CNS stem cell-derived neuronal precursors. J. Neurosci. 15, 5765-5778.

Alagappan, D., Lazzarino, D. A., Felling, R. J., Balan, M., Kotenko, S. V., and Levison, S. W. (2009). Brain injury expands the numbers of neural stem cells and progenitors in the SVZ by enhancing their responsiveness to EGF. ASN Neuro 1:e00009. doi:

Aloyz, R., Fawcett, J. P., Kaplan, D. R., Murphy, R. A., and Miller, F. D. (1999). Activity-dependent activation of TrkB neurotrophin receptors in the adult CNS. Learn. Mem. 6,

Altman, J., and Das, G. D. (1965). Autoradiographic and histological evidence of postnatal hippocampal neurogenesis in rats. J. Comp. Neurol. 124, 319-335.

Amankulor, N. M., Hambardzumyan, D., Pyonteck, S. M., Becher, O. J., Joyce, J. A., and Holland, E. C. (2009). Sonic hedgehog pathway activation is induced by acute brain injury and regulated by injuryrelated inflammation. J. Neurosci. 29, 10299-10308.

Andreu-Agullo, C., Maurin, T., Thompson, C. B., and Lai, E. C. (2012). Ars2 maintains neural stem-cell identity through direct transcriptional activation of Sox2. Nature 481, 195-198.

Arvidsson, A., Collin, T., Kirik, D., Kokaia, Z., and Lindvall, O. (2002). Neuronal replacement from endogenous precursors in the adult brain after stroke. Nat. Med. 8 , 963-970.

Ashton, R. S., Conway, A., Pangarkar, C., Bergen, J., Lim, K. I., Shah, P., et al. (2012). Astrocytes regulate adult hippocampal neurogenesis through ephrin-B signaling. Nat. Neurosci. 15, 1399-1406. 10.1042/AN20090002 216-231.

extrinsic factors still holds great promise of therapeutic potential, although much ground still remains to be covered.

\section{ACKNOWLEDGMENTS}

Ann M. Turnley is funded by a National Medical Health and Research Council of Australia Fellowship (\#628344).

Bajetto, A., Bonavia, R., Barbero, S., and Schettini, G. (2002). Characterization of chemokines and their receptors in the central nervous system: physiopathological implications. J. Neurochem. 82, 1311-1329.

Baldauf, K., and Reymann, K. G. (2005). Influence of EGF/bFGF treatment on proliferation, early neurogenesis and infarct volume after transient focal ischemia. Brain Res. 1056, 158-167.

Bambakidis, N. C., Petrullis, M., Kui, X., Rothstein, B., Karampelas, I., Kuang, Y., et al. (2012). Improvement of neurological recovery and stimulation of neural progenitor cell proliferation by intrathecal administration of Sonic hedgehog. J. Neurosurg. 116, 1114-1120.

Bambakidis, N. C., Wang, R. Z., Franic, L., and Miller, R. H. (2003). Sonic hedgehog-induced neural precursor proliferation after adult rodent spinal cord injury. J. Neurosurg. 99, 70-75.

Barkho, B. Z., Munoz, A. E., Li, X., Li L., Cunningham, L. A., and Zhao, X. (2008). Endogenous matrix metalloproteinase (MMP)-3 and MMP9 promote the differentiation and migration of adult neural progenitor cells in response to chemokines. Stem Cells 26, 3139-3149.

Bath, K. G., Mandairon, N., Jing, D., Rajagopal, R., Kapoor, R. Chen, Z. Y., et al. (2008). Variant brain-derived neurotrophic factor (Val66Met) alters adult olfactory bulb neurogenesis and spontaneous olfactory discrimination. J. Neurosci. 28, 2383-2393.

Benraiss, A., Chmielnicki, E., Lerner, K., Roh, D., and Goldman, S. A. (2001). Adenoviral brainderived neurotrophic factor induces both neostriatal and olfactory neuronal recruitment from endogenous progenitor cells in the adult forebrain. J. Neurosci. 21, 6718-6731.

Bergami, M., Rimondini, R., Santi, S. Blum, R., Gotz, M., and Canossa, M. (2008). Deletion of TrkB in adult progenitors alters newborn neuron integration into hippocampal circuits and increases anxiety-like behavior. Proc. Natl. Acad. Sci. U.S.A. 105, 15570-15575.

Blizzard, C. A., Chuckowree, J. A., King, A. E., Hosie, K. A., McCormack, G. H., Chapman, J. A., et al. (2011). Focal damage to the adult rat neocortex induces wound healing accompanied by axonal sprouting and dendritic structural plasticity. Cereb. Cortex 21, 281-291.

Bonaguidi, M. A., McGuire, T., Hu, M., Kan, L., Samanta, J., and Kessler, J. A. (2005). LIF and BMP signaling generate separate and discrete types of GFAP-expressing cells. Development 132, 5503-5514.

Bonaguidi, M. A., Peng, C. Y., McGuire, T., Falciglia, G., Gobeske, K. T. Czeisler, C., et al. (2008). Noggin expands neural stem cells in the adult hippocampus. J. Neurosci. 28, 9194-9204.

Boneva, N. B., and Yamashima, T. (2012). New insights into "GPR40CREB interaction in adult neurogenesis" specific for primates. Hippocampus 22, 896-905.

Bracko, O., Singer, T., Aigner, S., Knobloch, M., Winner, B., Ray, J., et al. (2012). Gene expression profiling of neural stem cells and their neuronal progeny reveals IGF2 as a regulator of adult hippocampal neurogenesis. J. Neurosci. 32, 3376-3387.

Brill, M. S., Ninkovic, J., Winpenny, E., Hodge, R. D., Ozen, I., Yang, R., et al. (2009). Adult generation of glutamatergic olfactory bulb interneurons. Nat. Neurosci. 12, 1524-1533.

Brill, M. S., Snapyan, M., Wohlfrom, H., Ninkovic, J., Jawerka, M. Mastick, G. S., et al. (2008). A dlx2and pax6-dependent transcriptional code for periglomerular neuron specification in the adult olfactory bulb. J. Neurosci. 28, 6439-6452.

Buffo, A., Vosko, M. R., Erturk, D. Hamann, G. F., Jucker, M., Rowitch, D., et al. (2005). Expression pattern of the transcription factor Olig2 in response to brain injuries: implications for neuronal repair. Proc. Natl. Acad. Sci. U.S.A. 102, 18183-18188.

Bull, N. D., and Bartlett, P. F. (2005). The adult mouse hippocampal progenitor is neurogenic but not a stem cell. J. Neurosci. 25, 10815-10821. 
Burk, K., Desoeuvre, A., Boutin, C., Smith, M. A., Kroger, S., Bosio, A., et al. (2012). Agrin-signaling is necessary for the integration of newly generated neurons in the adult olfactory bulb. J. Neurosi. 32, 3759-3764.

Calvo, C. F., Fontaine, R. H., Soueid, J., Tammela, T., Makinen, T., AlfaroCervello, C., et al. (2011). Vascular endothelial growth factor receptor 3 directly regulates murine neurogenesis. Genes Dev. 25, 831-844.

Carreira, B. P., Morte, M. I., Inacio, A., Costa, G., Rosmaninho-Salgado, J., Agasse, F., et al. (2010). Nitric oxide stimulates the proliferation of neural stem cells bypassing the epidermal growth factor receptor. Stem Cells 28, 1219-1230.

Carreira, B. P., Morte, M. I., Lourenco, A. S., Santos, A. I., Inacio, A., Ambrosio, A. F., et al. (2012). Differential contribution of the guanylyl cyclase-cyclic GMPprotein kinase G pathway to the proliferation of neural stem cells stimulated by nitric oxide. Neurosignals doi: 10.1159/000332811. [Epub ahead of print].

Cartier, L., Hartley, O., DuboisDauphin, M., and Krause, K. H. (2005). Chemokine receptors in the central nervous system: role in brain inflammation and neurodegenerative diseases. Brain Res. Brain Res. Rev. 48, 16-42.

Catchpole, T., and Henkemeyer, M. (2011). EphB2 tyrosine kinasedependent forward signaling in migration of neuronal progenitors that populate and form a distinct region of the dentate niche. J. Neurosci. 31, 11472-11483.

Cate, H. S., Sabo, J. K., Merlo, D., Kemper, D., Aumann, T. D., Robinson, J., et al. (2010). Modulation of bone morphogenic protein signalling alters numbers of astrocytes and oligodendroglia in the subventricular zone during cuprizone-induced demyelination. J. Neurochem. 115, 11-22.

Cayre, M., Canoll, P., and Goldman, J. E. (2009). Cell migration in the normal and pathological postnatal mammalian brain. Prog. Neurobiol. 88, 41-63.

Chazal, G., Durbec, P., Jankovski, A., Rougon, G., and Cremer, H. (2000). Consequences of neural cell adhesion molecule deficiency on cell migration in the rostral migratory stream of the mouse. J. Neurosci. 20, 1446-1457.

Chen, K., Henry, R. A., Hughes, S. M., and Connor, B. (2007a). Creating a neurogenic environment: the role of BDNF and FGF2. Mol. Cell. Neurosci. 36, 108-120.

Chen, Z. Y., Asavaritikrai, P., Prchal, J. T., and Noguchi, C. T. (2007b). Endogenous erythropoietin signaling is required for normal neural progenitor cell proliferation. J. Biol. Chem. 282, 25875-25883.

Chen, L. P., Li, Z. F., Ping, M., Li, R., Liu, J., Xie, X. H., et al. (2012). Regulation of Olig2 during astroglial differentiation in the subventricular zone of a cuprizoneinduced demyelination mouse model. Neuroscience 221, 96-107.

Cheng, C. M., Cohen, M., Tseng, V., and Bondy, C. A. (2001). Endogenous IGF1 enhances cell survival in the postnatal dentate gyrus. J. Neurosci. Res. 64, 341-347.

Cheung, A., Newland, P. L., Zaben, M., Attard, G. S., and Gray, W. P. (2012). Intracellular nitric oxide mediates neuroproliferative effect of neuropeptide $y$ on postnatal hippocampal precursor cells. J. Biol. Chem. 287, 20187-20196.

Chirumamilla, S., Sun, D., Bullock, M. R., and Colello, R. J. (2002). Traumatic brain injury induced cell proliferation in the adult mammalian central nervous system. J. Neurotrauma 19, 693-703.

Chumley, M. J., Catchpole, T., Silvany, R. E., Kernie, S. G., and Henkemeyer, M. (2007). EphB receptors regulate stem/progenitor cell proliferation, migration, and polarity during hippocampal neurogenesis. J. Neurosci. 27, 13481-13490.

Colak, D., Mori, T., Brill, M. S., Pfeifer, A., Falk, S., Deng, C., et al. (2008). Adult neurogenesis requires Smad4-mediated bone morphogenic protein signaling in stem cells. J. Neurosci. 28, 434-446.

Colin-Castelan, D., Phillips-Farfan, B. V., Gutierrez-Ospina, G., FuentesFarias, A. L., Baez-Saldana, A., Padilla-Cortes, P., et al. (2011). EphB4 is developmentally and differentially regulated in blood vessels throughout the forebrain neurogenic niche in the mouse brain: implications for vascular remodeling. Brain Res. 1383, 90-98.

Conover, J. C., Doetsch, F., GarciaVerdugo, J. M., Gale, N. W., Yancopoulos, G. D., and AlvarezBuylla, A. (2000). Disruption of Eph/ephrin signaling affects migration and proliferation in the adult subventricular zone. Nat. Neurosci. 3, 1091-1097.

Cooper, O., and Isacson, O. (2004). Intrastriatal transforming growth factor alpha delivery to a model of Parkinson's disease induces proliferation and migration of endogenous adult neural progenitor cells without differentiation into dopaminergic neurons. J. Neurosci. 24, 8924-8931.

Courtes, S., Vernerey, J., Pujadas, L., Magalon, K., Cremer, H., Soriano, E., et al. (2011). Reelin controls progenitor cell migration in the healthy and pathological adult mouse brain. PLOS ONE 6:e20430. doi: 10.1371/journal.pone.0020430

Craig, C. G., Tropepe, V., Morshead, C. M., Reynolds, B. A., Weiss, S., and Van Der Kooy, D. (1996). In vivo growth factor expansion of endogenous subependymal neural precursor cell populations in the adult mouse brain. J. Neurosci. 16, 2649-2658.

Cremer, H., Lange, R., Christoph, A., Plomann, M., Vopper, G., Roes, J., et al. (1994). Inactivation of the $\mathrm{N}$-CAM gene in mice results in size reduction of the olfactory bulb and deficits in spatial learning. Nature 367, 455-459.

Dash, P. K., Mach, S. A., and Moore, A. N. (2001). Enhanced neurogenesis in the rodent hippocampus following traumatic brain injury. J. Neurosci. Res. 63, 313-319.

Del Valle, K., Theus, M. H., Bethea, J. R., Liebl, D. J., and Ricard, J. (2011). Neural progenitors proliferation is inhibited by EphB3 in the developing subventricular zone. Int. J. Dev. Neurosci. 29, 9-14.

Dempsey, R. J., and Kalluri, H. S. (2007). Ischemia-induced neurogenesis: role of growth factors. Neurosurg. Clin. N. Am. 18, 183-190, xi.

Denham, M., Bye, C., Leung, J., Conley, B. J., Thompson, L. H., and Dottori, M. (2012). Glycogen synthase kinase 3beta and activin/nodal inhibition in human embryonic stem cells induces a pre-neuroepithelial state that is required for specification to a floor plate cell lineage. Stem Cells 30, 2400-2411.

Depaepe, V., Suarez-Gonzalez, N., Dufour, A., Passante, L., Gorski, J. A., Jones, K. R., et al. (2005). Ephrin signalling controls brain size by regulating apoptosis of neural progenitors. Nature 435, 1244-1250.

Doeppner, T. R., Bretschneider, E. Doehring, M., Segura, I., Senturk, A., Acker-Palmer, A., et al. (2011). Enhancement of endogenous neurogenesis in ephrin-B3 deficient mice after transient focal cerebral ischemia. Acta Neuropathol. 122, 429-442.

Doetsch, F., Petreanu, L., Caille, I., Garcia-Verdugo, J. M., and
Alvarez-Buylla, A. (2002). EGF converts transit-amplifying neurogenic precursors in the adult brain into multipotent stem cells. Neuron 36 1021-1034.

Donovan, M. H., Yamaguchi, M., and Eisch, A. J. (2008). Dynamic expression of TrkB receptor protein on proliferating and maturing cells in the adult mouse dentate gyrus. Hippocampus 18, 435-439.

Duan, X., Chang, J. H., Ge, S., Faulkner, R. L., Kim, J. Y., Kitabatake, Y., et al. (2007). DisruptedIn-Schizophrenia 1 regulates integration of newly generated neurons in the adult brain. Cell 130, 1146-1158.

Dummula, K., Vinukonda, G., Chu, P., Xing, Y., Hu, F., Mailk, S. et al. (2011). Bone morphogenetic protein inhibition promotes neurological recovery after intraventricular hemorrhage. J. Neurosci. 31, 12068-12082.

Dziembowska, M., Tham, T. N., Lau, P., Vitry, S., Lazarini, F., and DuboisDalcq, M. (2005). A role for CXCR4 signaling in survival and migration of neural and oligodendrocyte precursors. Glia 50, 258-269.

Ehm, O., Goritz, C., Covic, M., Schaffner, I., Schwarz, T. J., Karaca, E., et al. (2010). RBPJkappadependent signaling is essential for long-term maintenance of neural stem cells in the adult hippocampus. J. Neurosci. 30, 13794-13807.

Ernst, M., and Jenkins, B. J. (2004). Acquiring signalling specificity from the cytokine receptor gp130. Trends Genet. 20, 23-32.

Fabes, J., Anderson, P., Brennan, C., and Bolsover, S. (2007). Regenerationenhancing effects of EphA4 blocking peptide following corticospinal tract injury in adult rat spinal cord. Eur. J. Neurosci. 26, 2496-2505.

Faigle, R., and Song, H. (2012). Signaling mechanisms regulating adult neural stem cells and neurogenesis. Biochim. Biophys. Acta. pii: S0304-4165(12)00257-7. doi: 10.1016/j.bbagen.2012.09.002. [Epub ahead of print].

Favaro, R., Valotta, M., Ferri, A. L., Latorre, E., Mariani, J., Giachino, C., et al. (2009). Hippocampal development and neural stem cell maintenance require Sox2-dependent regulation of Shh. Nat. Neurosci. 12, 1248-1256.

Fernando, R. N., Eleuteri, B., Abdelhady, S., Nussenzweig, A., Andang, M., and Ernfors, P. (2011). Cell cycle restriction by histone H2AX limits proliferation of adult neural stem cells. Proc. Natl. Acad. Sci. U.S.A. 108, 5837-5842. 
Freund, T. F., and Buzsaki, G. (1996). Interneurons of the hippocampus. Hippocampus 6, 347-470.

Frielingsdorf, H., Simpson, D. R., Thal, L. J., and Pizzo, D. P. (2007). Nerve growth factor promotes survival of new neurons in the adult hippocampus. Neurobiol. Dis. 26, 47-55.

Gajera, C. R., Emich, H., Lioubinski, O., Christ, A., Beckervordersandforth-Bonk, R. Yoshikawa, K., et al. (2010). LRP2 in ependymal cells regulates BMP signaling in the adult neurogenic niche. J. Cell Sci. 123, 1922-1930.

Gao, X., and Chen, J. (2009). Conditional knockout of brainderived neurotrophic factor in the hippocampus increases death of adult-born immature neurons following traumatic brain injury. J. Neurotrauma 26, 1325-1335.

Gao, X., Smith, G. M., and Chen, J. (2009a). Impaired dendritic development and synaptic formation of postnatal-born dentate gyrus granular neurons in the absence of brain-derived neurotrophic factor signaling. Exp. Neurol. 215, 178-190.

Gao, Z., Ure, K., Ables, J. L., Lagace, D. C., Nave, K. A., Goebbels, S., et al. (2009b). Neurod1 is essential for the survival and maturation of adultborn neurons. Nat. Neurosci. 12, 1090-1092.

Gao, Y., Vasilyev, D. V., Goncalves, M. B., Howell, F. V., Hobbs, C., Reisenberg, M., et al. (2010). Loss of retrograde endocannabinoid signaling and reduced adult neurogenesis in diacylglycerol lipase knock-out mice. J. Neurosci. 30, 2017-2024.

Gascon, E., Dayer, A. G., Sauvain, M. O., Potter, G., Jenny, B., De Roo, M., et al. (2006). GABA regulates dendritic growth by stabilizing lamellipodia in newly generated interneurons of the olfactory bulb. J. Neurosci. 26, 12956-12966.

Ge, S., Goh, E. L., Sailor, K. A., Kitabatake, Y., Ming, G. L., and Song, H. (2006). GABA regulates synaptic integration of newly generated neurons in the adult brain. Nature 439, 589-593.

Goings, G. E., Sahni, V., and Szele, F. G. (2004). Migration patterns of subventricular zone cells in adult mice change after cerebral cortex injury. Brain Res. 996, 213-226.

Goldshmit, Y., Galea, M. P., Bartlett, P. F., and Turnley, A. M. (2006a). EphA4 regulates central nervous system vascular formation. J. Comp. Neurol. 497, 864-875.

Goldshmit, Y., McLenachan, S., and Turnley, A. (2006b). Roles of Eph receptors and ephrins in the normal and damaged adult CNS. Brain Res. Rev. 52, 327-345.

Goldshmit, Y., Galea, M. P., Wise, G., Bartlett, P. F., and Turnley, A. M. (2004). Axonal regeneration and lack of astrocytic gliosis in EphA4-deficient mice. J. Neurosci. 24, 10064-10073.

Goldshmit, Y., Spanevello, M. D., Tajouri, S., Li, L., Rogers, F., Pearse, M., et al. (2011). EphA4 blockers promote axonal regeneration and functional recovery following spinal cord injury in mice. PLOS ONE 6:e24636. doi: 10.1371/journal.pone.0024636

Gomez-Pinedo, U., Rodrigo, R., Cauli, O., Herraiz, S., Garcia-Verdugo, J. M., Pellicer, B., et al. (2010). cGMP modulates stem cells differentiation to neurons in brain in vivo. Neuroscience 165, 1275-1283.

Goncalves, M. B., Suetterlin, P., Yip, P., Molina-Holgado, F. Walker, D. J., Oudin, M. J., et al. (2008). A diacylglycerol lipase-CB2 cannabinoid pathway regulates adult subventricular zone neurogenesis in an age-dependent manner. Mol. Cell. Neurosci. 38, 526-536.

Gonzalez-Perez, O., RomeroRodriguez, R., Soriano-Navarro, M. Garcia-Verdugo, J. M., and AlvarezBuylla, A. (2009). Epidermal growth factor induces the progeny of subventricular zone type B cells to migrate and differentiate into oligodendrocytes. Stem Cells 27 2032-2043.

Gordon, R. J., McGregor, A. L., and Connor, B. (2009). Chemokines direct neural progenitor cell migration following striatal cell loss. Mol. Cell. Neurosci. 41, 219-232.

Gross, R. E., Mehler, M. F., Mabie, P. C., Zang, Z., Santschi, L., and Kessler, J. A. (1996). Bone morphogenetic proteins promote astroglial lineage commitment by mammalian subventricular zone progenitor cells. Neuron 17, 595-606.

Guillemot, F. (2007). Cell fate specification in the mammalian telencephalon. Prog. Neurobiol. $83,37-52$.

Hack, I., Bancila, M., Loulier, K., Carroll, P., and Cremer, H. (2002). Reelin is a detachment signal in tangential chain-migration during postnatal neurogenesis. Nat. Neurosci. 5, 939-945.

Hack, M. A., Saghatelyan, A., De Chevigny, A., Pfeifer, A., AsheryPadan, R., Lledo, P. M., et al. (2005). Neuronal fate determinants of adult olfactory bulb neurogenesis. Nat. Neurosci. 8, 865-872.
Hampton, D. W., Asher, R. A., Kondo, T., Steeves, J. D., Ramer, M. S. and Fawcett, J. W. (2007). A potential role for bone morphogenetic protein signalling in glial cell fate determination following adult central nervous system injury in vivo. Eur. J. Neurosci. 26, 3024-3035.

Hara, Y., Nomura, T., Yoshizaki, K., Frisen, J., and Osumi, N. (2010) Impaired hippocampal neurogenesis and vascular formation in ephrin-A5-deficient mice. Stem Cells 28, 974-983.

He, P., and Shen, Y. (2009). Interruption of beta-catenin signaling reduces neurogenesis in Alzheimer's disease. J. Neurosci. 29, 6545-6557.

Heinrich, P. C., Behrmann, I., Haan, S., Hermanns, H. M., MullerNewen, G., and Schaper, F. (2003) Principles of interleukin (IL)-6type cytokine signalling and its regulation. Biochem. J. 374, 1-20.

Henry, R. A., Hughes, S. M., and Connor, B. (2007). AAV-mediated delivery of BDNF augments neurogenesis in the normal and quinolinic acid-lesioned adult rat brain. Eur. J. Neurosci. 25, 3513-3525.

Hill, M. N., Titterness, A. K., Morrish, A. C., Carrier, E. J., Lee, T. T., Gil-Mohapel, J., et al. (2010). Endogenous cannabinoid signaling is required for voluntary exercise-induced enhancement of progenitor cell proliferation in the hippocampus. Hippocampus 20 513-523.

Hiroi, M., and Ohmori, Y. (2003). The transcriptional coactivator CREBbinding protein cooperates with STAT1 and NF-kappa B for synergistic transcriptional activation of the CXC ligand 9/monokine induced by interferon-gamma gene. J. Biol. Chem. 278, 651-660.

Holmberg, J., Armulik, A., Senti, K. A., Edoff, K., Spalding, K., Momma, S., et al. (2005). Ephrin-A2 reverse signaling negatively regulates neura progenitor proliferation and neurogenesis. Genes Dev. 19, 462-471.

Honda, S., Toda, K., Tozuka, Y., Yasuzawa, S., Iwabuchi, K., and Tomooka, Y. (2007). Migration and differentiation of neural cell lines transplanted into mouse brains. Neurosci. Res. 59, 124-135.

Howell, O. W., Doyle, K., Goodman, J. H., Scharfman, H. E., Herzog, H., Pringle, A., et al. (2005). Neuropeptide Y stimulates neuronal precursor proliferation in the post-natal and adult dentate gyrus. J. Neurochem. 93, 560-570.

Hu, H., Tomasiewicz, H., Magnuson, T., and Rutishauser, U. (1996). The role of polysialic acid in migration of olfactory bulb interneuron precursors in the subventricular zone. Neuron 16, 735-743.

Hurtado-Chong, A., Yusta-Boyo, M. J., Vergano-Vera, E., Bulfone, A., De Pablo, F., and Vicario-Abejon, C. (2009). IGF-I promotes neuronal migration and positioning in the olfactory bulb and the exit of neuroblasts from the subventricular zone. Eur. J. Neurosci. 30, 742-755.

Im, S. H., Yu, J. H., Park, E. S., Lee, J. E., Kim, H. O., Park, K. I., et al. (2010). Induction of striatal neurogenesis enhances functional recovery in an adult animal model of neonatal hypoxic-ischemic brain injury. Neuroscience 169, 259-268.

Imitola, J., Raddassi, K., Park, K. I., Mueller, F. J., Nieto, M., Teng, Y. D., et al. (2004). Directed migration of neural stem cells to sites of CNS injury by the stromal cell-derived factor lalpha/CXC chemokine receptor 4 pathway. Proc. Natl. Acad. Sci. U.S.A. 101, 18117-18122.

Itoh, T., Satou, T., Ishida, H., Nishida, S., Tsubaki, M., Hashimoto, S., et al. (2009). The relationship between SDF-1alpha/CXCR4 and neural stem cells appearing in damaged area after traumatic brain injury in rats. Neurol. Res. 31, 90-102.

Jablonska, B., Aguirre, A., Raymond, M., Szabo, G., Kitabatake, Y., Sailor, K. A., et al. (2010). Chordininduced lineage plasticity of adult SVZ neuroblasts after demyelination. Nat. Neurosci. 13, 541-550.

Jacques, T. S., Relvas, J. B., Nishimura, S., Pytela, R., Edwards, G. M., Streuli, C. H., et al. (1998). Neural precursor cell chain migration and division are regulated through different betal integrins. Development 125, 3167-3177.

Jessberger, S., Toni, N., Clemenson, G. D. Jr., Ray, J., and Gage, F. H. (2008). Directed differentiation of hippocampal stem/progenitor cells in the adult brain. Nat. Neurosci. 11, 888-893.

Jia, C., Cussen, A. R., and Hegg, C. C. (2011). ATP differentially upregulates fibroblast growth factor 2 and transforming growth factor alpha in neonatal and adult mice: effect on neuroproliferation. Neuroscience 177, 335-346.

Jiang, W., Zhang, Y., Xiao, L., Van Cleemput, J., Ji, S. P., Bai, G., et al. (2005). Cannabinoids promote embryonic and adult hippocampus neurogenesis and produce anxiolytic- and antidepressantlike effects. J. Clin. Invest. 115, 3104-3116. 
Jiao, J., and Chen, D. F. (2008). Induction of neurogenesis in nonconventional neurogenic regions of the adult central nervous system by niche astrocyte-produced signals. Stem Cells 26, 1221-1230.

Jin, K., Sun, Y., Xie, L., Peel, A., Mao, X. O., Batteur, S., et al. (2003). Directed migration of neuronal precursors into the ischemic cerebral cortex and striatum. Mol. Cell. Neurosci. 24, 171-189.

Jing, X., Miwa, H., Sawada, T., Nakanishi, I., Kondo, T., Miyajima, M., et al. (2012). EphrinAl-mediated dopaminergic neurogenesis and angiogenesis in a rat model of Parkinson's disease. PLoS ONE 7:e32019. doi: 10.1371/journal.pone.0032019

Johanson, C., Stopa, E., Baird, A., and Sharma, H. (2011). Traumatic brain injury and recovery mechanisms: peptide modulation of periventricular neurogenic regions by the choroid plexus-CSF nexus. J. Neural Transm. 118, 115-133.

Kadota, T., Shingo, T., Yasuhara, T., Tajiri, N., Kondo, A., Morimoto, T., et al. (2009). Continuous intraventricular infusion of erythropoietin exerts neuroprotective/rescue effects upon Parkinson's disease model of rats with enhanced neurogenesis. Brain Res. 1254, 120-127.

Kako, E., Kaneko, N., Aoyama, M., Hida, H., Takebayashi, H., Ikenaka, K., et al. (2012). Subventricular zone-derived oligodendrogenesis in injured neonatal white matter in mice enhanced by a nonerythropoietic erythropoietin derivative. Stem Cells 30, 2234-2247.

Kamimura, D., Ishihara, K., and Hirano, T. (2003). IL-6 signal transduction and its physiological roles: the signal orchestration model. Rev. Physiol. Biochem. Pharmacol. 149, 1-38.

Kandasamy, M., Couillard-Despres, S., Raber, K. A., Stephan, M., Lehner, B., Winner, B., et al. (2010). Stem cell quiescence in the hippocampal neurogenic niche is associated with elevated transforming growth factor-beta signaling in an animal model of Huntington disease. J. Neuropathol. Exp. Neurol. 69, 717-728.

Katakowski, M., Zhang, Z., Decarvalho, A. C., and Chopp, M. (2005). EphB2 induces proliferation and promotes a neuronal fate in adult subventricular neural precursor cells. Neurosci. Lett. 385, 204-209.

Kernie, S. G., Erwin, T. M., and Parada, L. F. (2001). Brain remodeling due to neuronal and astrocytic proliferation after controlled cortical injury in mice. J. Neurosci. Res. 66, 317-326.

Khodosevich, K., Watanabe, Y., and Monyer, H. (2011). EphA4 preserves postnatal and adult neural stem cells in an undifferentiated state in vivo. J. Cell Sci. 124, 1268-1279.

Kim, E. J., Ables, J. L., Dickel, L. K. Eisch, A. J., and Johnson, J. E. (2011a). Ascl1 (Mash1) defines cells with long-term neurogenic potential in subgranular and subventricular zones in adult mouse brain. PLOS ONE 6:e18472. doi: 10.1371/ journal.pone.0018472

Kim, W. R., Chun, S. K., Kim, T. W., Kim, H., Ono, K., Takebayashi, H., et al. (2011b). Evidence for the spontaneous production but massive programmed cell death of new neurons in the subcallosal zone of the postnatal mouse brain. Eur. J. Neurosci. 33, 599-611.

Kim, E. J., Leung, C. T., Reed, R. R., and Johnson, J. E. (2007). In vivo analysis of Ascll defined progenitors reveals distinct developmental dynamics during adult neurogenesis and gliogenesis. J. Neurosci. 27, 12764-12774.

Kim, J. Y., Liu, C. Y., Zhang, F., Duan, X., Wen, Z., Song, J., et al. (2012). Interplay between DISC1 and GABA signaling regulates neurogenesis in mice and risk for schizophrenia. Cell 148, 1051-1064.

Kirschenbaum, B., and Goldman, S. A. (1995). Brain-derived neurotrophic factor promotes the survival of neurons arising from the adult rat forebrain subependymal zone. Proc. Natl. Acad. Sci. U.S.A. 92, 210-214.

Kojima, T., Hirota, Y., Ema, M. Takahashi, S., Miyoshi, I., Okano, H., et al. (2010). Subventricular zone-derived neural progenitor cells migrate along a blood vessel scaffold toward the post-stroke striatum. Stem Cells 28, 545-554.

Kolb, B., Morshead, C., Gonzalez, C. Kim, M., Gregg, C., Shingo, T., et al. (2007). Growth factor-stimulated generation of new cortical tissue and functional recovery after stroke damage to the motor cortex of rats. J. Cereb. Blood Flow Metab. 27, 983-997.

Krathwohl, M. D., and Kaiser, J. L. (2004). Chemokines promote quiescence and survival of human neural progenitor cells. Stem Cells 22, 109-118.

Kreuzberg, M., Kanov, E., Timofeev, O., Schwaninger, M., Monyer, H., and Khodosevich, K. (2010). Increased subventricular zone-derived cortical neurogenesis after ischemic lesion. Exp. Neurol. 226, 90-99.
Kuhn, H. G., Winkler, J., Kempermann, G., Thal, L. J., and Gage, F. H (1997). Epidermal growth factor and fibroblast growth factor- 2 have different effects on neural progenitors in the adult rat brain. J. Neurosci. 17, 5820-5829.

Kuwabara, T., Hsieh, J., Muotri, A., Yeo, G., Warashina, M., Lie, D. C., et al. (2009). Wnt-mediated activation of NeuroD1 and retroelements during adult neurogenesis. Nat. Neurosci. 12, 1097-1105.

Larsson, E., Mandel, R. J., Klein, R. L., Muzyczka, N., Lindvall, O. and Kokaia, Z. (2002). Suppression of insult-induced neurogenesis in adult rat brain by brain-derived neurotrophic factor. Exp. Neurol. 177, 1-8.

Lavado, A., Lagutin, O. V., Chow, L. M., Baker, S. J., and Oliver, G. (2010). Prox1 is required for granule cell maturation and intermediate progenitor maintenance during brain neurogenesis. PLoS Biol. 8:e1000460. doi: 10.1371/journal.pbio. 1000460

Leconte, C., Bihel, E., Lepelletier, F. X., Bouet, V., Saulnier, R., Petit, E. et al. (2011). Comparison of the effects of erythropoietin and its carbamylated derivative on behaviour and hippocampal neurogenesis in mice. Neuropharmacology 60, 354-364.

Lee, J., Duan, W., and Mattson, M. P. (2002). Evidence that brain-derived neurotrophic factor is required for basal neurogenesis and mediates, in part, the enhancement of neurogenesis by dietary restriction in the hippocampus of adult mice. J. Neurochem. 82, 1367-1375.

Lei, Z. N., Liu, F., Zhang, L. M. Huang, Y. L., and Sun, F. Y. (2012) $\mathrm{Bcl}-2$ increases stroke-induced striatal neurogenesis in adult brains by inhibiting BMP-4 function via activation of beta-catenin signaling. Neurochem. Int. 61, 34-42.

Lei, Z. N., Zhang, L. M., and Sun, F. Y. (2008). Beta-catenin siRNA inhibits ischemia-induced striatal neurogenesis in adult rat brain following a transient middle cerebral artery occlusion. Neurosci. Lett. 435 , 108-112.

Le Magueresse, C., Alfonso, J., Bark, C., Eliava, M., Khrulev, S., and Monyer, H. (2012). Subventricular zone-derived neuroblasts use vasculature as a scaffold to migrate radially to the cortex in neonatal mice. Cereb. Cortex 22, 2285-2296.

Leong, S. Y., Faux, C. H., Turbic, A., Dixon, K. J., and Turnley, A. M. (2011). The Rho kinase pathway regulates mouse adult neural precursor cell migration. Stem Cells 29, 332-343.

Li, X., Sun, C., Lin, C., Ma, T. Madhavan, M. C., Campbell, K., et al. (2011). The transcription factor $\mathrm{Sp8}$ is required for the production of parvalbumin-expressing interneurons in the olfactory bulb. J. Neurosci. 31, 8450-8455.

Li, Y., Luikart, B. W., Birnbaum, S., Chen, J., Kwon, C. H., Kernie, S. G., et al. (2008). TrkB regulates hippocampal neurogenesis and governs sensitivity to antidepressive treatment. Neuron 59, 399-412.

Lie, D. C., Colamarino, S. A., Song, H. J., Desire, L., Mira, H., Consiglio, A., et al. (2005). Wnt signalling regulates adult hippocampal neurogenesis. Nature 437, 1370-1375.

Lim, D. A., Tramontin, A. D., Trevejo, J. M., Herrera, D. G., GarciaVerdugo, J. M., and Alvarez-Buylla, A. (2000). Noggin antagonizes BMP signaling to create a niche for adult neurogenesis. Neuron 28, 713-726.

Lindberg, O. R., Brederlau, A., Jansson, A., Nannmark, U., Cooper-Kuhn, C., and Kuhn, H. G. (2012). Characterization of epidermal growth factor-induced dysplasia in the adult rat subventricular zone. Stem Cells Dev. 21, 1356-1366.

Liu, X., Hawkes, E., Ishimaru, T., Tran, T., and Sretavan, D. W. (2006) EphB3: an endogenous mediator of adult axonal plasticity and regrowth after CNS injury. J. Neurosci. 26, 3087-3101.

Lu, D., Mahmood, A., Qu, C., Goussev, A., Schallert, T., and Chopp, M. (2005). Erythropoietin enhances neurogenesis and restores spatial memory in rats after traumatic brain injury. J. Neurotrauma 22, 1011-1017.

Lu, K. T., Sun, C. L., Wo, P. Y., Yen, H. H., Tang, T. H., Ng, M. C. et al. (2011). Hippocampal neurogenesis after traumatic brain injury is mediated by vascular endothelial growth factor receptor2 and the Raf/MEK/ERK cascade. J. Neurotrauma 28, 441-450.

Lum, M., Croze, E., Wagner, C., McLenachan, S., Mitrovic, B., and Turnley, A. M. (2009). Inhibition of neurosphere proliferation by IFNgamma but not IFNbeta is coupled to neuronal differentiation. J. Neuroimmunol. 206, 32-38.

Maekawa, M., Takashima, N., Arai, Y., Nomura, T., Inokuchi, K., Yuasa, S., et al. (2005). Pax6 is required for production and maintenance of progenitor cells in postnatal hippocampal neurogenesis. Genes Cells 10, 1001-1014. 
Magavi, S. S., Leavitt, B. R., and Macklis, J. D. (2000). Induction of neurogenesis in the neocortex of adult mice. Nature 405, 951-955.

Magill, S. T., Cambronne, X. A., Luikart, B. W., Lioy, D. T., Leighton, B. H., Westbrook, G. L., et al. (2010). microRNA-132 regulates dendritic growth and arborization of newborn neurons in the adult hippocampus. Proc. Natl. Acad. Sci. U.S.A. 107, 20382-20387.

Malaterre, J., Mantamadiotis, T., Dworkin, S., Lightowler, S., Yang, Q., Ransome, M. I., et al. (2008). $\mathrm{c}-\mathrm{Myb}$ is required for neural progenitor cell proliferation and maintenance of the neural stem cell niche in adult brain. Stem Cells 26, 173-181.

Mao, Y., Ge, X., Frank, C. L., Madison, J. M., Koehler, A. N., Doud, M. K., et al. (2009). Disrupted in schizophrenia 1 regulates neuronal progenitor proliferation via modulation of GSK3beta/betacatenin signaling. Cell 136, 1017-1031.

McLenachan, S., Lum, M. G., Waters, M. J., and Turnley, A. M. (2009). Growth hormone promotes proliferation of adult neurosphere cultures. Growth Horm. IGF Res. 19, 212-218.

Mehler, M. F., Mabie, P. C., Zhu, G., Gokhan, S., and Kessler, J. A. (2000). Developmental changes in progenitor cell responsiveness to bone morphogenetic proteins differentially modulate progressive CNS lineage fate. Dev. Neurosci. 22, 74-85.

Meng, Y., Xiong, Y., Mahmood, A., Zhang, Y., Qu, C., and Chopp, M. (2011). Dose-dependent neurorestorative effects of delayed treatment of traumatic brain injury with recombinant human erythropoietin in rats. J. Neurosurg. 115, 550-560.

Ming, G. L., and Song, H. (2011). Adult neurogenesis in the mammalian brain: significant answers and significant questions. Neuron $70,687-702$

Mira, H., Andreu, Z., Suh, H., Lie, D. C., Jessberger, S., Consiglio, A., et al. (2010). Signaling through BMPR-IA regulates quiescence and long-term activity of neural stem cells in the adult hippocampus. Cell Stem Cell 7, 78-89.

Moreno-Lopez, B., Romero-Grimaldi, C., Noval, J. A., Murillo-Carretero, M., Matarredona, E. R., and Estrada, C. (2004). Nitric oxide is a physiological inhibitor of neurogenesis in the adult mouse subventricular zone and olfactory bulb. J. Neurosci. 24, 85-95.
Morris, D. C., Zhang, Z. G., Wang, Y., Zhang, R. L., Gregg, S., Liu, X. S., et al. (2007). Wnt expression in the adult rat subventricular zone after stroke. Neurosci. Lett. 418, 170-174.

Muller, S., Chakrapani, B. P., Schwegler, H., Hofmann, H. D., and Kirsch, M. (2009). Neurogenesis in the dentate gyrus depends on ciliary neurotrophic factor and signal transducer and activator of transcription 3 signaling. Stem Cells 27, 431-441.

Munro, K. M., Perreau, V. M., and Turnley, A. M. (2012). Differential gene expression in the EphA4 knockout spinal cord and analysis of the inflammatory response following spinal cord injury. PLoS ONE 7:e37635. doi: 10.1371/journal.pone.0037635

Murase, S., and Horwitz, A. F. (2002). Deleted in colorectal carcinoma and differentially expressed integrins mediate the directional migration of neural precursors in the rostral migratory stream. J. Neurosci. 22, 3568-3579.

Nakatomi, H., Kuriu, T., Okabe, S., Yamamoto, S., Hatano, O., Kawahara, N., et al. (2002). Regeneration of hippocampal pyramidal neurons after ischemic brain injury by recruitment of endogenous neural progenitors. Cell 110, 429-441.

Namba, T., Ming, G. L., Song, H., Waga, C., Enomoto, A., Kaibuchi, K., et al. (2011). NMDA receptor regulates migration of newly generated neurons in the adult hippocampus via Disrupted-In-Schizophrenia 1 (DISC1). J. Neurochem. 118, 34-44.

Ning, R., Xiong, Y., Mahmood, A., Zhang, Y., Meng, Y., Qu, C., et al. (2011). Erythropoietin promotes neurovascular remodeling and long-term functional recovery in rats following traumatic brain injury. Brain Res. 1384, 140-150.

Ninomiya, M., Yamashita, T., Araki, N., Okano, H., and Sawamoto, K. (2006). Enhanced neurogenesis in the ischemic striatum following EGF-induced expansion of transit-amplifying cells in the subventricular zone. Neurosci. Lett. 403, 63-67.

Nomura, T., Goritz, C., Catchpole, T., Henkemeyer, M., and Frisen, J. (2010). EphB signaling controls lineage plasticity of adult neural stem cell niche cells. Cell Stem Cell 7, 730-743.

Ohab, J. J., Fleming, S., Blesch, A., and Carmichael, S. T. (2006). A neurovascular niche for neurogenesis after stroke. J. Neurosci. 26, 13007-13016.
O'Keeffe, G. C., and Barker, R. A. (2011). Dopamine stimulates epidermal growth factor release from adult neural precursor cells derived from the subventricular zone by a disintegrin and metalloprotease. Neuroreport 22, 956-958.

O'Keeffe, G. C., Tyers, P., Aarsland, D., Dalley, J. W., Barker, R. A., and Caldwell, M. A. (2009). Dopamine-induced proliferation of adult neural precursor cells in the mammalian subventricular zone is mediated through EGF. Proc. Natl. Acad. Sci. U.S.A. 106, 8754-8759.

Oudin, M. J., Gajendra, S., Williams, G., Hobbs, C., Lalli, G., and Doherty, P. (2011a). Endocannabinoids regulate the migration of subventricular zonederived neuroblasts in the postnatal brain. J. Neurosci. 31, 4000-4011.

Oudin, M. J., Hobbs, C., and Doherty, P. (2011b). DAGL-dependent endocannabinoid signalling: roles in axonal pathfinding, synaptic plasticity and adult neurogenesis. Eur. J. Neurosci. 34, 1634-1646.

Overman, J. J., Clarkson, A. N., Wanner, I. B., Overman, W. T. Eckstein, I., Maguire, J. L., et al. (2012). A role for ephrin-A5 in axonal sprouting, recovery, and activity-dependent plasticity after stroke. Proc. Natl. Acad. Sci. U.S.A. 109, E2230-E2239.

Oya, S., Yoshikawa, G., Takai, K., Tanaka, J., Higashiyama, S., Saito, N., et al. (2008). Region-specific proliferative response of neura progenitors to exogenous stimulation by growth factors following ischemia. Neuroreport 19, 805-809.

Ozen, I., Galichet, C., Watts, C., Parras, C., Guillemot, F., and Raineteau, O. (2007). Proliferating neuronal progenitors in the postnatal hippocampus transiently express the proneural gene Ngn2. Eur. J. Neurosci. 25, 2591-2603.

Packer, M. A., Stasiv, Y., Benraiss, A., Chmielnicki, E., Grinberg, A., Westphal, H., et al. (2003). Nitric oxide negatively regulates mammalian adult neurogenesis. Proc. Natl. Acad. Sci. U.S.A. 100, 9566-9571.

Pankratova, S., Gu, B., Kiryushko, D., Korshunova, I., Kohler, L. B., Rathje, M., et al. (2012). A new agonist of the erythropoietin receptor, Epobis, induces neurite outgrowth and promotes neuronal survival. J. Neurochem. 121, 915-923.

Parent, J. M., Vexler, Z. S., Gong, C., Derugin, N., and Ferriero, D. M. (2002). Rat forebrain neurogenesis and striatal neuron replacement after focal stroke. Ann. Neurol. 52, 802-813.

Park, C., Sohn, Y., Shin, K. S., Kim, J., Ahn, H., and Huh, Y. (2003). The chronic inhibition of nitric oxide synthase enhances cell proliferation in the adult rat hippocampus. Neurosci. Lett. 339, 9-12.

Piccin, D., and Morshead, C. M. (2011). Wnt signaling regulates symmetry of division of neural stem cells in the adult brain and in response to injury. Stem Cells 29, 528-538.

Pincus, D. W., Keyoung, H. M., Harrison-Restelli, C., Goodman, R. R., Fraser, R. A., Edgar, M., et al. (1998). Fibroblast growth factor2/brain-derived neurotrophic factor-associated maturation of new neurons generated from adult human subependymal cells. Ann. Neurol. 43, 576-585.

Platel, J. C., Dave, K. A., Gordon, V., Lacar, B., Rubio, M. E., and Bordey, A. (2010). NMDA receptors activated by subventricular zone astrocytic glutamate are critical for neuroblast survival prior to entering a synaptic network. Neuron 65 , 859-872.

Qiu, R., Wang, X., Davy, A., Wu, C. Murai, K., Zhang, H., et al. (2008). Regulation of neural progenitor cell state by ephrin-B. J. Cell Biol. 181, 973-983.

Ramaswamy, S., Goings, G. E., Soderstrom, K. E., Szele, F. G., and Kozlowski, D. A. (2005). Cellular proliferation and migration following a controlled cortical impact in the mouse. Brain Res. 1053, 38-53.

Ransome, M. I., and Turnley, A. M. (2007). Systemically delivered Erythropoietin transiently enhances adult hippocampal neurogenesis. J. Neurochem. 102, 1953-1965.

Ransome, M. I., and Turnley, A. M. (2008a). Erythropoietin promotes axonal growth in a model of neuronal polarization. Mol. Cell. Neurosci. 38, 537-547.

Ransome, M. I., and Turnley, A. M. (2008b). Growth hormone signaling and hippocampal neurogenesis: insights from genetic models. Hippocampus 18, 1034-1050.

Reif, A., Schmitt, A., Fritzen, S., Chourbaji, S., Bartsch, C., Urani, A., et al. (2004). Differential effect of endothelial nitric oxide synthase (NOS-III) on the regulation of adult neurogenesis and behaviour. Eur. J. Neurosci. 20, 885-895.

Reynolds, B. A., and Weiss, S. (1992). Generation of neurons and astrocytes from isolated cells of the adult mammalian central nervous system. Science 255, 1707-1710. 
Richards, L. J., Kilpatrick, T. J., and Bartlett, P. F. (1992). De novo generation of neuronal cells from the adult mouse brain. Proc. Natl. Acad. Sci. U.S.A. 89, 8591-8595.

Richardson, R. M., Sun, D., and Bullock, M. R. (2007). Neurogenesis after traumatic brain injury. Neurosurg. Clin. N. Am. 18, 169-181, xi.

Robin, A. M., Zhang, Z. G., Wang, L., Zhang, R. L., Katakowski, M., Zhang, L., et al. (2006). Stromal cell-derived factor lalpha mediates neural progenitor cell motility after focal cerebral ischemia. J. Cereb. Blood Flow Metab. 26, 125-134.

Rodger, J., Vitale, P. N., Tee, L. B., King, C. E., Bartlett, C. A., Fall, A., et al. (2004). EphA/ephrin-A interactions during optic nerve regeneration: restoration of topography and regulation of ephrin-A2 expression. Mol. Cell. Neurosci. 25, 56-68.

Sabo, J. K., Aumann, T. D., Merlo, D., Kilpatrick, T. J., and Cate, H. S. (2011). Remyelination is altered by bone morphogenic protein signaling in demyelinated lesions. J. Neurosci. 31, 4504-4510.

Sabo, J. K., Kilpatrick, T. J., and Cate, H. S. (2009). Effects of bone morphogenic proteins on neural precursor cells and regulation during central nervous system injury. Neurosignals 17, 255-264.

Saghatelyan, A., Roux, P., Migliore, M., Rochefort, C., Desmaisons, D., Charneau, P., et al. (2005). Activity-dependent adjustments of the inhibitory network in the olfactory bulb following early postnatal deprivation. Neuron 46, 103-116.

Schabitz, W. R., Steigleder, T., Cooper-Kuhn, C. M., Schwab, S., Sommer, C., Schneider, A., et al. (2007). Intravenous brain-derived neurotrophic factor enhances poststroke sensorimotor recovery and stimulates neurogenesis. Stroke 38, 2165-2172.

Scobie, K. N., Hall, B. J., Wilke, S. A., Klemenhagen, K. C., FujiiKuriyama, Y., Ghosh, A., et al. (2009). Kruppel-like factor 9 is necessary for late-phase neuronal maturation in the developing dentate gyrus and during adult hippocampal neurogenesis. J. Neurosci. 29, 9875-9887.

Scott, H. J., Stebbing, M. J., Walters, C. E., McLenachan, S., Ransome, M. I., Nichols, N. R., et al. (2006). Differential effects of SOCS2 on neuronal differentiation and morphology. Brain Res. 1067, 138-145.

Seroogy, K. B., Lundgren, K. H., Lee, D. C., Guthrie, K. M., and Gall, C. M. (1993). Cellular localization of transforming growth factoralpha mRNA in rat forebrain. J. Neurochem. 60, 1777-1782.

Shear, D. A., Tate, M. C., Archer, D. R., Hoffman, S. W., Hulce, V. D. Laplaca, M. C., et al. (2004). Neural progenitor cell transplants promote long-term functional recovery after traumatic brain injury. Brain Res. 1026, 11-22.

Shen, Q., Wang, Y., Kokovay, E., Lin, G., Chuang, S. M., Goderie, S. K., et al. (2008). Adult SVZ stem cells lie in a vascular niche: a quantitative analysis of niche cellcell interactions. Cell Stem Cell 3, 289-300.

Shingo, T., Sorokan, S. T., Shimazaki, T., and Weiss, S. (2001). Erythropoietin regulates the in vitro and in vivo production of neuronal progenitors by mammalian forebrain neural stem cells. J. Neurosci. 21, 9733-9743.

Shruster, A., Ben-Zur, T., Melamed, E., and Offen, D. (2012). Wnt signaling enhances neurogenesis and improves neurological function after focal ischemic injury. PLOS ONE 7:e40843. doi: 10.1371/journal.pone.0040843

Sims, J. R., Lee, S. W., Topalkara, K., Qiu, J., Xu, J., Zhou, Z., et al. (2009). Sonic hedgehog regulates ischemia/hypoxia-induced neural progenitor proliferation. Stroke 40, 3618-3626.

Sun, D., Bullock, M. R., Altememi, N., Zhou, Z., Hagood, S., Rolfe, A., et al. (2010). The effect of epidermal growth factor in the injured brain after trauma in rats. J. Neurotrauma 27, 923-938.

Sun, D., Bullock, M. R., McGinn, M. J., Zhou, Z., Altememi, N., Hagood, S., et al. (2009). Basic fibroblast growth factor-enhanced neurogenesis contributes to cognitive recovery in rats following traumatic brain injury. Exp. Neurol. 216, 56-65.

Sun, L. Y., Evans, M. S., Hsieh, J., Panici, J., and Bartke, A. (2005a). Increased neurogenesis in dentate gyrus of long-lived Ames dwarf mice. Endocrinology 146, 1138-1144.

Sun, Y., Jin, K., Childs, J. T., Xie, L., Mao, X. O., and Greenberg, D. A. (2005b). Neuronal nitric oxide synthase and ischemia-induced neurogenesis. J. Cereb. Blood Flow Metab. $25,485-492$.

Sundholm-Peters, N. L., Yang, H. K., Goings, G. E., Walker, A. S., and Szele, F. G. (2005). Subventricular zone neuroblasts emigrate toward cortical lesions. J. Neuropathol. Exp. Neurol. 64, 1089-1100.
Suyama, S., Sunabori, T., Kanki, H., Sawamoto, K., Gachet, C., Koizumi, S., et al. (2012). Purinergic signaling promotes proliferation of adult mouse subventricular zone cells. J. Neurosci. 32, 9238-9247.

Suyama, T., Furuya, M., Nishiyama, M., Kasuya, Y., Kimura, S., Ichikawa, T., et al. (2005). Up-regulation of the interferon gamma (IFNgamma)-inducible chemokines IFN-inducible T-cell alpha chemoattractant and monokine induced by IFN-gamma and of their receptor CXC receptor 3 in human renal cell carcinoma. Cancer 103 258-267.

Tavazoie, M., Van Der Veken, L., SilvaVargas, V., Louissaint, M., Colonna, L., Zaidi, B., et al. (2008). A specialized vascular niche for adult neural stem cells. Cell Stem Cell 3, 279-288.

Teixeira, C. M., Kron, M. M., Masachs, N., Zhang, H., Lagace, D. C., Martinez, A., et al. (2012). Cellautonomous inactivation of the reelin pathway impairs adult neurogenesis in the hippocampus. J. Neurosci. 32, 12051-12065.

Teramoto, T., Qiu, J., Plumier, J. C. and Moskowitz, M. A. (2003) EGF amplifies the replacement of parvalbumin-expressing striatal interneurons after ischemia. J. Clin. Invest. 111, 1125-1132.

Theus, M. H., Ricard, J., Bethea, J. R., and Liebl, D. J. (2010). EphB3 limits the expansion of neural progenitor cells in the subventricular zone by regulating $\mathrm{p} 53$ during homeostasis and following traumatic brain injury. Stem Cells 28, 1231-1242.

Thored, P., Wood, J., Arvidsson, A., Cammenga, J., Kokaia, Z., and Lindvall, O. (2007). Long-term neuroblast migration along blood vessels in an area with transient angiogenesis and increased vascularization after stroke. Stroke 38, 3032-3039.

Tonchev, A. B., and Yamashima, T. (2006). Differential neurogenic potential of progenitor cells in dentate gyrus and CAl sector of the postischemic adult monkey hippocampus. Exp. Neurol. 198, 101-113.

Tonchev, A. B., Yamashima, T., and Chaldakov, G. N. (2007). Distribution and phenotype of proliferating cells in the forebrain of adult macaque monkeys after transient global cerebral ischemia. Adv. Anat. Embryol. Cell Biol. 191, 1-106.

Tonchev, A. B., Yamashima, T., Sawamoto, K., and Okano, H. (2005). Enhanced proliferation of progenitor cells in the subventricular zone and limited neuronal production in the striatum and neocortex of adult macaque monkeys after global cerebral ischemia. J. Neurosci. Res. 81, 776-788.

Tonchev, A. B., Yamashima, T., Zhao, L., and Okano, H. (2003a). Differential proliferative response in the postischemic hippocampus, temporal cortex, and olfactory bulb of young adult macaque monkeys. Glia 42, 209-224.

Tonchev, A. B., Yamashima, T., Zhao, L., Okano, H. J., and Okano, H. (2003b). Proliferation of neural and neuronal progenitors after global brain ischemia in young adult macaque monkeys. Mol. Cell. Neurosci. 23, 292-301.

Tran, P. B., Ren, D., Veldhouse, T. J., and Miller, R. J. (2004). Chemokine receptors are expressed widely by embryonic and adult neural progenitor cells. J. Neurosci. Res. 76, 20-34.

Tsai, P. T., Ohab, J. J., Kertesz, N. Groszer, M., Matter, C., Gao, J., et al. (2006). A critical role of erythropoietin receptor in neurogenesis and post-stroke recovery. J. Neurosci. 26, 1269-1274

Turbic, A., Leong, S. Y., and Turnley, A. M. (2011). Chemokines and inflammatory mediators interact to regulate adult murine neural precursor cell proliferation, survival and differentiation. PLOS ONE 6:e25406. doi: 10.1371/journal.pone.0025406

Tureyen, K., Vemuganti, R., Bowen, K. K., Sailor, K. A., and Dempsey, R. J. (2005). EGF and FGF-2 infusion increases post-ischemic neural progenitor cell proliferation in the adult rat brain. Neurosurgery 57 1254-1263. discussion: 1254-1263.

Turnley, A. M., and Bartlett, P. F. (2000). Cytokines that signal through the leukemia inhibitory factor receptor-beta complex in the nervous system. J. Neurochem. 74, 889-899.

Turnley, A. M., Faux, C. H., Rietze, R. L., Coonan, J. R., and Bartlett, P. F. (2002). Suppressor of cytokine signaling 2 regulates neuronal differentiation by inhibiting growth hormone signaling. Nat. Neurosci. 5, 1155-1162.

Van Hoecke, A., Schoonaert, L., Lemmens, R., Timmers, M., Staats, K. A., Laird, A. S., et al. (2012). EPHA4 is a disease modifier of amyotrophic lateral sclerosis in animal models and in humans. Nat. Med. 18, 1418-1422.

Wang, L., Zhang, Z., Wang, Y., Zhang, R., and Chopp, M. (2004a). Treatment of stroke with erythropoietin enhances neurogenesis 
and angiogenesis and improves neurological function in rats. Stroke 35, 1732-1737.

Wang, L., Zhang, Z., Zhang, R., Hafner, M. S., Wong, H. K., Jiao, Z., et al. (2004b). Erythropoietin up-regulates SOCS2 in neuronal progenitor cells derived from SVZ of adult rat. Neuroreport 15, 1225-1229.

Wang, L., Zhang, Z. G., Gregg, S. R., Zhang, R. L., Jiao, Z., Letourneau, Y., et al. (2007). The Sonic hedgehog pathway mediates carbamylated erythropoietin-enhanced proliferation and differentiation of adult neural progenitor cells. J. Biol. Chem. 282, 32462-32470.

Wang, L., Zhang, Z. G., Zhang, R. L., Gregg, S. R., Hozeska-Solgot, A., Letourneau, Y., et al. (2006). Matrix metalloproteinase 2 (MMP2) and MMP9 secreted by erythropoietinactivated endothelial cells promote neural progenitor cell migration. J. Neurosci. 26, 5996-6003.

Wang, X., Mao, X., Xie, L., Greenberg, D. A., and Jin, K. (2009). Involvement of Notch1 signaling in neurogenesis in the subventricular zone of normal and ischemic rat brain in vivo. J. Cereb. Blood Flow Metab. 29, 1644-1654.

Wang, Y., Imitola, J., Rasmussen, S., O'Connor, K. C., and Khoury, S. J. (2008). Paradoxical dysregulation of the neural stem cell pathway sonic hedgehog-Gli1 in autoimmune encephalomyelitis and multiple sclerosis. Ann. Neurol. 64, 417-427.

Watanabe, T., Okuda, Y., Nonoguchi, N., Zhao, M. Z., Kajimoto, Y., Furutama, D., et al. (2004). Postischemic intraventricular administration of FGF-2 expressing adenoviral vectors improves neurologic outcome and reduces infarct volume after transient focal cerebral ischemia in rats. J. Cereb. Blood Flow Metab. 24, 1205-1213.

Wells, A. J., Vink, R., Blumbergs, P. C., Brophy, B. P., Helps, S. C., Knox, S. J., et al. (2012). A surgical model of permanent and transient middle cerebral artery stroke in the sheep. PLoS ONE 7:e42157. doi: 10.1371/journal.pone.0042157

Wexler, E. M., Paucer, A., Kornblum, H. I., Palmer, T. D., and Geschwind, D. H. (2009). Endogenous Wnt signaling maintains neural progenitor cell potency. Stem Cells 27, 1130-1141.

White, B. D., Nathe, R. J., Maris, D. O., Nguyen, N. K., Goodson, J.
M., Moon, R. T., et al. (2010). Beta-catenin signaling increases in proliferating NG2+ progenitors and astrocytes during post-traumatic gliogenesis in the adult brain. Stem Cells 28, 297-307.

Winner, B., Couillard-Despres, S., Geyer, M., Aigner, R., Bogdahn, U., Aigner, L., et al. (2008). Dopaminergic lesion enhances growth factor-induced striatal neuroblast migration. J. Neuropathol. Exp. Neurol. 67, 105-116.

Winner, B., Desplats, P., Hagl, C., Klucken, J., Aigner, R., Ploetz, S., et al. (2009). Dopamine receptor activation promotes adult neurogenesis in an acute Parkinson model. Exp. Neurol. 219, 543-552.

Wittko, I. M., Schanzer, A., Kuzmichev, A., Schneider, F. T., Shibuya, M., Raab, S., et al. (2009). VEGFR-1 regulates adult olfactory bulb neurogenesis and migration of neural progenitors in the rostral migratory stream in vivo. J. Neurosci. 29, 8704-8714.

Wolf, S. A., Bick-Sander, A., Fabel, K., Leal-Galicia, P., Tauber, S., Ramirez-Rodriguez, G., et al. (2010). Cannabinoid receptor CB1 mediates baseline and activityinduced survival of new neurons in adult hippocampal neurogenesis. Cell Commun. Signal. 8:12. doi: 10.1186/1478-811X-8-12

Wong, G., Goldshmit, Y., and Turnley, A. M. (2004). Interferon-gamma but not TNF alpha promotes neuronal differentiation and neurite outgrowth of murine adult neural stem cells. Exp. Neurol. 187, 171-177.

Wu, W., Wong, K., Chen, J., Jiang, Z., Dupuis, S., Wu, J. Y., et al. (1999). Directional guidance of neuronal migration in the olfactory system by the protein Slit. Nature 400, 331-336.

Xiong, Y., Zhang, Y., Mahmood, A., Meng, Y., Qu, C., and Chopp, M. (2011). Erythropoietin mediates neurobehavioral recovery and neurovascular remodeling following traumatic brain injury in rats by increasing expression of vascular endothelial growth factor. Transl. Stroke Res. 2, 619-632.

Yamashita, T., Ninomiya, M., Hernandez Acosta, P., GarciaVerdugo, J. M., Sunabori, T., Sakaguchi, M., et al. (2006). Subventricular zone-derived neuroblasts migrate and differentiate into mature neurons in the poststroke adult striatum. J. Neurosci. 26, 6627-6636.

Yoshimura, S., Takagi, Y., Harada, J., Teramoto, T., Thomas, S. S., Waeber, C., et al. (2001). FGF-2 regulation of neurogenesis in adult hippocampus after brain injury. Proc. Natl. Acad. Sci. U.S.A. 98, 5874-5879.

Young, C. C., Brooks, K. J., Buchan, A. M., and Szele, F. G. (2011). Cellular and molecular determinants of stroke-induced changes in subventricular zone cell migration. Antioxid. Redox Signal. 14, 1877-1888.

Young, K. M., Merson, T. D., Sotthibundhu, A., Coulson, E. J., and Bartlett, P. F. (2007). p75 neurotrophin receptor expression defines a population of BDNFresponsive neurogenic precursor cells. J. Neurosci. 27, 5146-5155.

Zhang, L., Chopp, M., Zhang, R. L., Wang, L., Zhang, J., Wang, Y., et al. (2010). Erythropoietin amplifies stroke-induced oligodendrogenesis in the rat. PLOS ONE 5:e11016. doi: 10.1371/journal.pone.0011016

Zhang, L., Zhang, Z., Zhang, R. L., Cui, Y., Lapointe, M. C., Silver, B., et al. (2006). Tadalafil, a long-acting type 5 phosphodiesterase isoenzyme inhibitor, improves neurological functional recovery in a rat model of embolic stroke. Brain Res. 1118, 192-198.

Zhang, R., Wang, L., Zhang, L., Chen, J., Zhu, Z., Zhang, Z., et al. (2003). Nitric oxide enhances angiogenesis via the synthesis of vascular endothelial growth factor and cGMP after stroke in the rat. Circ. Res. 92, 308-313.

Zhang, R., Zhang, L., Zhang, Z., Wang, Y., Lu, M., Lapointe, M., et al. (2001a). A nitric oxide donor induces neurogenesis and reduces functional deficits after stroke in rats. Ann. Neurol. 50, 602-611.

Zhang, R. L., Zhang, Z. G., Zhang, L., and Chopp, M. (2001b). Proliferation and differentiation of progenitor cells in the cortex and the subventricular zone in the adult rat after focal cerebral ischemia. Neuroscience 105, 33-41.

Zhang, R. L., Chopp, M., Roberts, C., Jia, L., Wei, M., Lu, M., et al. (2011). Ascll lineage cells contribute to ischemia-induced neurogenesis and oligodendrogenesis. J. Cereb. Blood Flow Metab. 31, 614-625.
Zhang, Y., Chopp, M., Mahmood, A., Meng, Y., Qu, C., and Xiong, Y. (2012). Impact of inhibition of erythropoietin treatment-mediated neurogenesis in the dentate gyrus of the hippocampus on restoration of spatial learning after traumatic brain injury. Exp. Neurol. 235, 336-344.

Zhao, M., Li, D., Shimazu, K., Zhou, Y. X., Lu, B., and Deng, C. X. (2007). Fibroblast growth factor receptor-1 is required for long-term potentiation, memory consolidation, and neurogenesis. Biol. Psychiatry 62, 381-390.

Zhu, D. Y., Liu, S. H., Sun, H. S., and Lu, Y. M. (2003). Expression of inducible nitric oxide synthase after focal cerebral ischemia stimulates neurogenesis in the adult rodent dentate gyrus. J. Neurosci. 23, 223-229.

Zhu, W., Cheng, S., Xu, G., Ma, M., Zhou, Z., Liu, D., et al. (2011). Intranasal nerve growth factor enhances striatal neurogenesis in adult rats with focal cerebral ischemia. Drug Deliv. 18, 338-343.

Zigova, T., Pencea, V., Wiegand, S. J., and Luskin, M. B. (1998). Intraventricular administration of BDNF increases the number of newly generated neurons in the adult olfactory bulb. Mol. Cell. Neurosci. 11, 234-245.

Conflict of Interest Statement: The authors declare that the research was conducted in the absence of any commercial or financial relationships that could be construed as a potential conflict of interest.

Received: 30 October 2012; paper pending published: 30 November 2012; accepted: 30 December 2012; published online: 18 January 2013.

Citation: Christie KJ and Turnley AM (2013) Regulation of endogenous neural stem/progenitor cells for neural repairfactors that promote neurogenesis and gliogenesis in the normal and damaged brain. Front. Cell. Neurosci. 6:70. doi: 10.3389/fncel.2012.00070

Copyright (c) 2013 Christie and Turnley. This is an open-access article distributed under the terms of the Creative Commons Attribution License, which permits use, distribution and reproduction in other forums, provided the original authors and source are credited and subject to any copyright notices concerning any third-party graphics etc. 